\title{
Structurally Diverse Mitochondrial Branched Chain Aminotransferase (BCATm) Leads With Varying Binding Modes Identified by Fragment
} Screening

\author{
Jennifer A Borthwick ${ }^{* 1,3}$, Nicolas Ancellin ${ }^{2}$, Sophie M Bertrand ${ }^{1,3}$, Ryan P Bingham ${ }^{1}$, Paul S \\ Carter $^{1}$, Chun-wa Chung ${ }^{1}$, Ian Churcher ${ }^{1}$, Nerina Dodic ${ }^{2}$, Charlène Fournier ${ }^{1}$, Peter L Francis ${ }^{1}$, \\ Andrew Hobbs ${ }^{1}$, Craig Jamieson ${ }^{3}$, Stephen D Pickett ${ }^{1}$, Sarah E Smith ${ }^{1}$, Donald O’N Somers ${ }^{1}$, \\ Claus Spitzfaden ${ }^{1}$, Colin J Suckling ${ }^{3}$, Robert J Young ${ }^{1}$. \\ ${ }^{1}$ GlaxoSmithKline R\&D, Medicines Research Centre, Gunnels Wood Road, Stevenage, \\ Hertfordshire, SG1 2NY, UK. \\ ${ }^{2}$ GlaxoSmithKline R\&D, Les Ulis, Centre de Recherche, 25,27 Avenue du Québec, 91140 \\ Villebon sur Yvette, France. \\ ${ }^{3}$ Department of Pure and Applied Chemistry, University of Strathclyde, 295 Cathedral Street, \\ Glasgow, G1 1XL.
}

\begin{abstract}
Inhibitors of mitochondrial branched chain aminotransferase (BCATm), identified using fragment screening, are described. This was carried out using a combination of STD-NMR, thermal melt $\left(\mathrm{T}_{\mathrm{m}}\right)$ and biochemical assays to identify compounds that bound to BCATm, which were subsequently progressed to X-ray crystallography, where a number of exemplars showed significant diversity in their binding modes. The hits identified were supplemented by searching
\end{abstract}


and screening of additional analogues, which enabled the gathering of further X-ray data where the original hits had not produced liganded structures. The fragment hits were optimised using structure-based design, with some transfer of information between series, which enabled the identification of ligand efficient lead molecules with micromolar levels of inhibition, cellular activity, and good solubility.

\section{Introduction}

Mitochondrial branched chain aminotransferase (BCATm) is a metabolic enzyme which converts the branched chain amino acids (BCAAs), leucine, isoleucine and valine into their corresponding $\alpha$-keto acids. Over the past few years, evidence has appeared linking this enzyme to obesity in animals and humans; accordingly inhibition of this enzyme has potential as a treatment for obesity and related diseases. The BCATm isoform is expressed ubiquitously, with very high levels in the stomach, pancreas and salivary glands, consistent with its role in protein metabolism. ${ }^{1}$ Interestingly, BCATm knock-out mice are resistant to high-fat diet induced obesity and diabetes; ${ }^{2}$ these effects are believed to be caused by the establishment of an energy consuming cycle of protein synthesis and degradation. This phenotype is similar to that observed in humans who consume high protein diets or BCAA supplements and experience increased energy expenditure, lower appetite and ultimately, lower body weights. ${ }^{2}$ The role of BCATm and BCAAs in the aetiology of obesity is complex and not fully understood; knock-out and dietary studies discussed above, where high levels of BCAA appear to be associated with reduced risk of becoming obese, are complicated by studies of obese animals. Genetically mutated obese rodents and diet-induced obese mice and humans have all been shown to have reduced BCATm expression, resulting in higher BCAA levels than lean animals. ${ }^{3}$ 
The search for inhibitors of BCATm at GSK was pursued using three complementary methods; fragment screening, high throughput screening (HTS) and encoded library technology. This paper describes the diversity of chemical matter, displaying distinct binding modes discovered by fragment screening. Hybridization of one of these hits with an HTS hit led to a potent in vivo active series ${ }^{4}$ and a further series was identified by encoded library technology. ${ }^{5}$ Together, this package of work has shed much light on the variable binding modes observed with BCATm and is beginning to shed some light on the effects of specific pharmacological inhibition of BCATm by small molecules and the role of this enzyme in disease.

In a commentary ${ }^{6}$ on our Fragment Assisted Drug Design ${ }^{7}$ paper, the difficulty of the target was highlighted, as was the importance of having diverse chemical matter with appropriate in vivo activities to interrogate a target; this paper illustrates structural information describing diverse binding modes observed. In fragment screening, the lack of overlap between screening methods has been acknowledged ${ }^{8}$; this was observed in the progression of hits identified by the various methods in this fragment screen, perhaps compounded by the diversity of binding modes.

The fragment hits were clustered according to their distinct binding modes. Importantly, this study provides new structural understanding of this enzyme, with several binding pockets identified by the fragment screen, which were not occupied by either of the other series ${ }^{4,5}$. Additionally, further optimisation efforts on two of the fragment hit series are described, which represent useful starting points and give important structural pointers to enable the identification of structurally novel tools for further pharmacological studies.

\section{Results and Discussion}

\section{Fragment Screening}


FBDD techniques have become an integral part of the drug discovery process during the last decade. ${ }^{7,9,10}$ Standard components of the FBDD methodology include the use of biophysical screening and X-ray crystallography to enable the identification, optimisation and designed growth of inherently weakly binding ligands into potent lead molecules. ${ }^{11}$ Commonly, these methods have used a single form of the protein, for example, the apo or a cofactor bound state.

However, during enzyme turnover in solution, the dynamic changes in protein conformation and biochemical state present a number of potential binding opportunities. The use of a single form for screening in a binding assay may restrict the type of compounds that can be detected and characterised. In the extreme case, this arbitrary choice may preclude sampling the most tractable form of the enzyme. During the catalytic cycle (Scheme 1) PLP and PMP cofactor bound forms of BCATm are sampled. Pragmatically we therefore used both PLP and PMP forms in our studies where possible, as these can both be stably isolated.

At the start of the cycle, the cofactor pyridoxal phosphate (PLP) is covalently bound to the enzyme via a lysine residue (Lys-202) (Scheme 1). ${ }^{12}$ This lysine is then displaced by the $\alpha$ amine of an incoming BCAA substrate. The imine formed is hydrolysed to the corresponding $\alpha$ keto acid. In the course of the reaction, the co-factor is released from its covalent bond to the enzyme as pyridoxamine phosphate (PMP). A complementary half-reaction occurs to complete the cycle, whereby $\alpha$-ketoglutarate is transaminated to glutamate and the PLP form of the enzyme is regenerated. It was possible to characterise both the PLP and PMP forms of the enzyme (e.g. spectroscopically or by mass spectrometry) and to interconvert between these using an excess of either leucine or $\alpha$-keto glutarate as appropriate. 


\section{Scheme 1: Reaction cycle catalysed by BCATm}

A functional biochemical assay was designed to detect inhibitors of this pathway, making use of a coupled sequence of enzymes (Figure 1), whereby the glutamate product of BCATm activity was re-oxidised to $\alpha$-keto glutarate along with hydrogen peroxide by the enzyme glutamate oxidase. The peroxide thus generated was detected by reaction with 1-(3,7-dihydroxy-10Hphenoxazin-10-yl)ethanone to form resorufin, catalysed by the enzyme horseradish peroxidase. Decoupled parallel control wells, without the BCATm initiated step were added to detect any inhibitors of the coupled processes. A potential risk of carrying out fragment screening using such a coupled enzyme system was that genuine inhibitors of BCATm could be discarded as non-specific in nature due the higher chances of fragments interacting with more than one 
enzyme. Theoretical reasoning based on complexity, ${ }^{13}$ on which much of FBDD methodology is predicated, suggest that there is a higher probability of smaller molecules binding to any given protein than for larger molecules. Therefore, it is more likely that fragments binding to BCATm may also bind to the coupled enzyme glutamate oxidase than would be the case if this assay was used for a traditional HTS campaign with larger, more complex molecules. However, using this functional biochemical assay had the advantage that all biochemical forms of the protein necessary for reaction could be sampled, permitting the detection of inhibitors that inhibited only one of these forms.

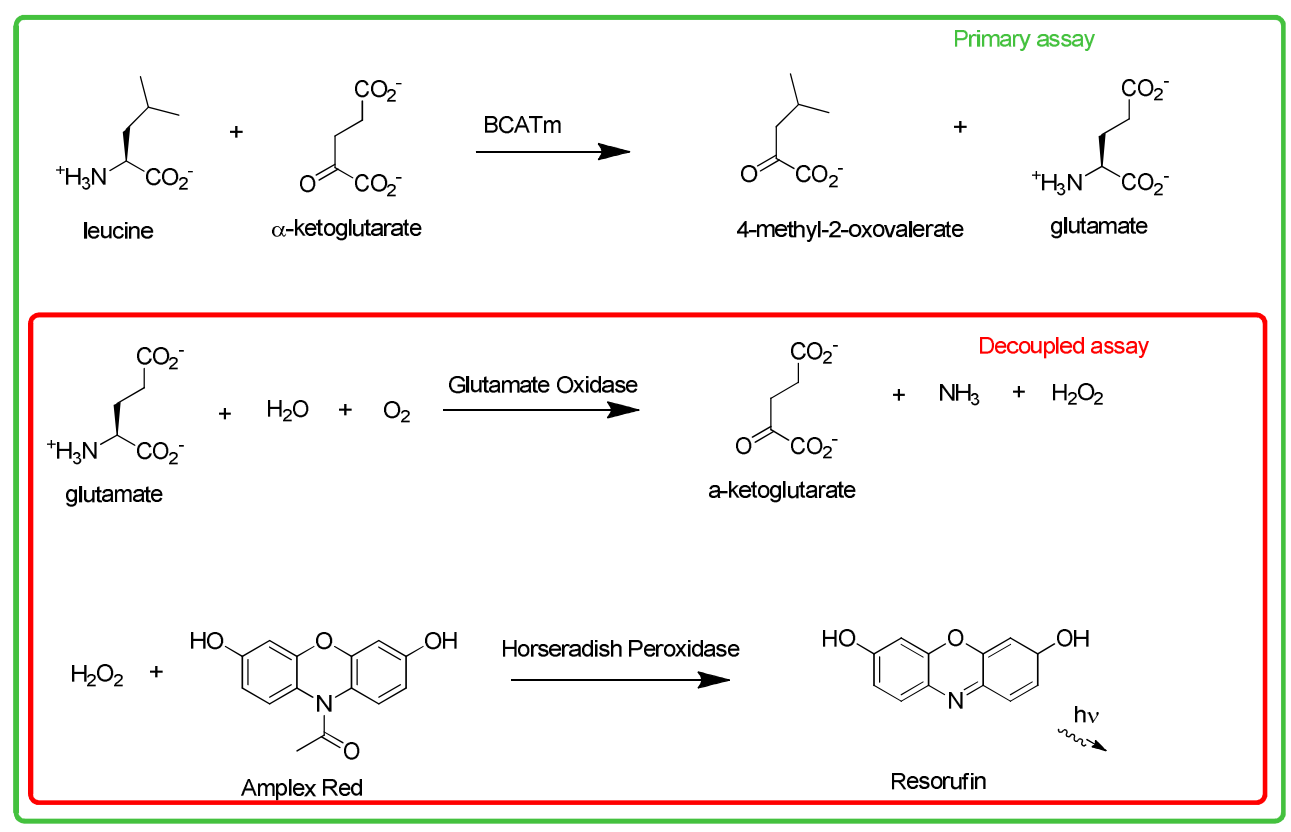

\section{Figure 1: Biochemical assay format}

As is common in fragment screening campaigns, complementary biophysical screening was also carried out to detect compounds which bound to BCATm; in this case NMR and thermal shift techniques were used. The saturation transfer difference (STD) NMR assay ${ }^{14}$ used a mixture of the PLP and PMP forms of the enzyme. Hits identified may interact with either, or potentially 
both, the PLP and PMP forms of the protein. However, as both forms are catalytically relevant the precise binding profile was not initially determined as all hits had the potential to yield functional inhibitors. The STD-NMR approach was complemented by a thermal shift screen $\left(\mathrm{T}_{\mathrm{m}}\right),{ }^{15}$ where both forms of the enzyme were independently assayed. This was necessary because of the very different denaturation temperatures of the PLP(E) and PMP(F) bound proteins, $73^{\circ} \mathrm{C}$ and $54^{\circ} \mathrm{C}$, respectively.

The GSK core fragment library of 1056 compounds was screened in parallel through all three assays and hit rates are shown in Figure 2. The crystallography was carried out by soaking high concentration solutions (40 - $60 \mathrm{mM}$ ) of the ligand of interest into preformed crystals of both PMP and PLP forms of the protein for one to fourteen days, sometimes yielding liganded crystals that gave datasets sufficient to unambiguously determine binding modes (resolutions in the range 1.8 - $2.4 \AA$ ). Although crystals of both the PLP and PMP forms of the BCATm were tried, the initial hits only yielded complexes with the more stable PLP protein. We therefore took the pragmatic decision to prioritise inhibitors for which crystal structures could be elucidated, thereby concentrating efforts on inhibitors of the PLP form of BCATm. 

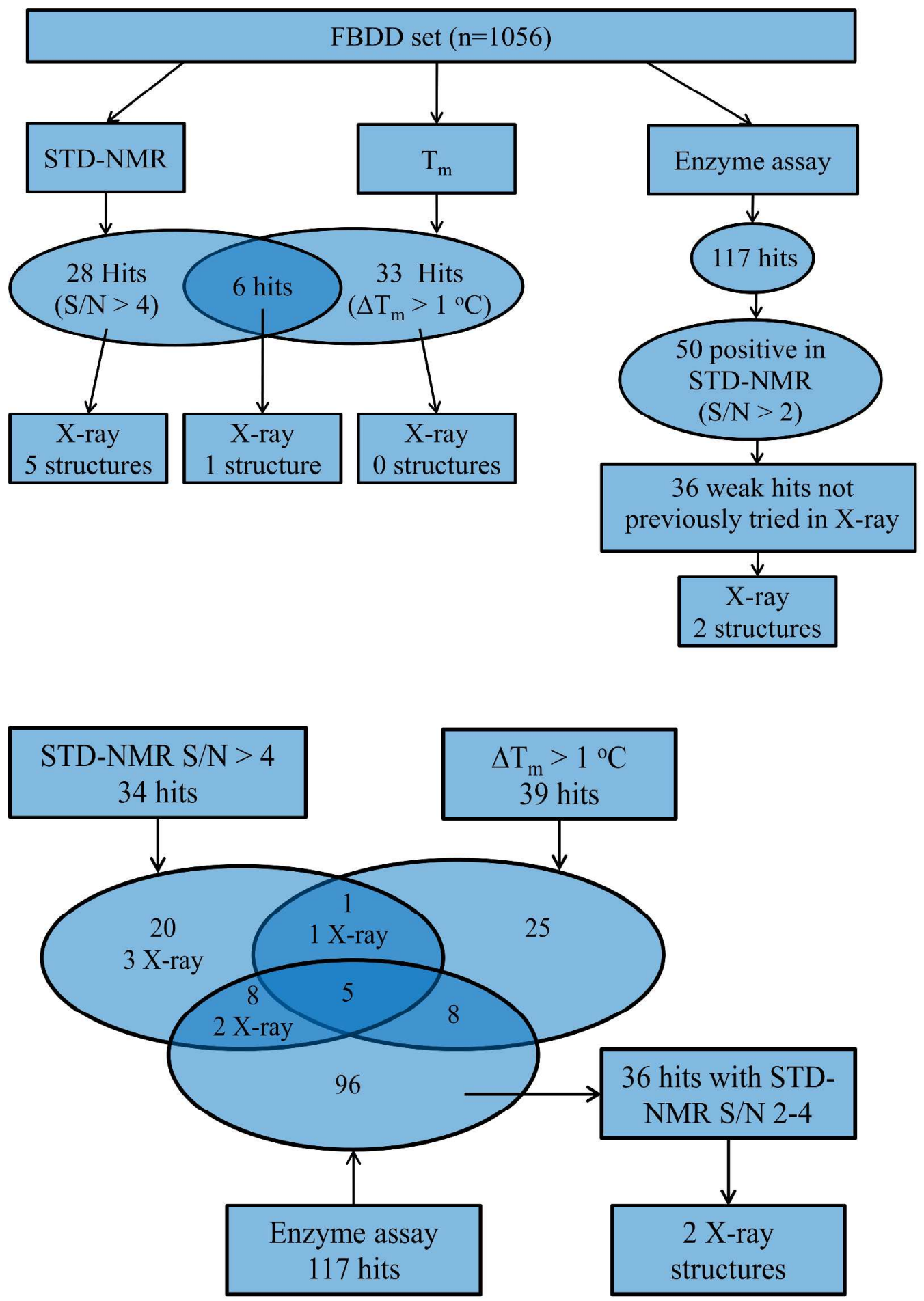

Figure 2: Flow and Venn diagrams illustrating the output of the fragment screening campaign, showing number of hits identified by each screening technique and the logic 


\section{employed for $X$-ray prioritisation, plus the distribution of those which yielded $X$-ray crystal structures.}

The output of the fragment screening is summarised in Figure 2. The different screening techniques produced different sets of hits, which is a common observation in FBDD campaigns ${ }^{8}$, as screening is carried out close to the limits of detection for the assays and different experimental conditions may favour a particular target conformation. All of the hits from either of the biophysical assays were progressed to X-ray crystallography. The STD-NMR experiment gave the better success rate in identifying apparent binders that led to liganded X-ray structures, with the orthogonal thermal shift experiment showing a relatively poor prediction of success. The biochemical assay had yielded a high number of specific hits, which could not all be progressed to crystallography, so the STD-NMR data was used to triage these hits, using a lower cut-off $(2 \times$ signal to noise, versus $4 \times$ signal to noise $)$ than was used in the initial selection of NMR hits.

Additional activities were carried out in an effort to increase the number of liganded X-ray structures as potential starting points for chemical optimisation. Five compounds identified were hits in both $\mathrm{T}_{\mathrm{m}}$ and NMR assays but failed to produce crystal structures. Given reasonable confidence that these compounds were genuinely binding to BCATm, structural analogues were sourced from the GSK compound collection and screened in the STD-NMR and biochemical assays. Analogue searching was performed by focussed substructure searching complemented by a GSK-developed workflow, FindAnalogues, specifically designed for fragment follow-up. FindAnalogues combines substructure and similarity searching methods with different descriptors and constraints on compound properties to identify suitable fragment like analogues from both in-house and external vendors (see Experimental for details). 80 compounds were 
selected from this exercise and screened. 32 compounds were identified with activity in one of the two assays, from which three yielded liganded structures where the original fragment hit had not $(\mathbf{1 2}, \mathbf{1 3}, \mathbf{1 5})$. An additional 120 similarly selected analogues were subsequently screened and yielded valuable SAR for compounds $\mathbf{4}$ and $\mathbf{5}$ as described below.

Concurrent with this fragment screen, a high throughput screen of the GSK HTS compound collection (1.7 million compounds) had been conducted. The single-shot percentage inhibition data and subsequent $\mathrm{XC}_{50}$ data were interrogated for compounds that were identified by the FindAnalogues search. Four analogues of $\mathbf{1}$ were identified with micromolar activity in the HTS and were submitted to crystallography, yielding additional liganded structures 9 and $\mathbf{1 0 .}$ 
2

3

4

5

6

7

8

9

10

11

12

13

14

15

16

17

18

19

20

21

22

23

24

25

26

27

28

29

30

31

32

33

34

35

36

37

38

39

40

41

42

43

44

45

46

47

48

49

50

51

52

53

54

55

56

57

58

59

60

\section{Fragment Hits}

\begin{tabular}{|c|c|c|c|c|c|c|c|c|}
\hline $\begin{array}{l}\text { Compound } \\
\text { Number }\end{array}$ & Structure & $\mathrm{pIC}_{50}$ & $\operatorname{clog} P$ & $\begin{array}{l}\text { Heavy } \\
\text { Atoms }\end{array}$ & LE & $\operatorname{LLE}_{A T}$ & Source & Binding Mode \\
\hline 1 & & $<2.9$ & 0.78 & 13 & & & STD-NMR & $\begin{array}{l}\text { PLP lipophilic pocket, } \\
\text { Hydrogen bond acceptor } \\
\text { to Ala-314 }\end{array}$ \\
\hline 2 & & $<2.9$ & 1.25 & 15 & & & $\begin{array}{l}\mathrm{T}_{\mathrm{m}} \text { and } \\
\text { STD-NMR }\end{array}$ & $\begin{array}{l}\text { PLP lipophilic pocket, } \\
\text { Hydrogen bond acceptor } \\
\text { to Ala-314 }\end{array}$ \\
\hline 3 & & $<2.9$ & 1.57 & 15 & & & STD-NMR & $\begin{array}{l}\text { PLP lipophilic pocket, } \\
\text { Hydrogen bond acceptor } \\
\text { to Ala-314 }\end{array}$ \\
\hline 4 & & $4.2^{\mathrm{a}}$ & 0.62 & 15 & 0.38 & 0.43 & $\begin{array}{l}\text { STD-NMR } \\
\text { and } \\
\text { biochemical }\end{array}$ & $\begin{array}{l}\pi \text { - stacking to Phe-30, } \\
\text { Hydrogen bond acceptor } \\
\text { to Lys-79 }\end{array}$ \\
\hline 5 & & $3.0^{\mathrm{b}}$ & 1.31 & 15 & 0.27 & 0.26 & $\begin{array}{l}\text { STD-NMR } \\
\text { and } \\
\text { biochemical }\end{array}$ & $\begin{array}{l}\pi \text { - stacking to Phe-30, } \\
\text { PLP lipophilic pocket }\end{array}$ \\
\hline 6 & & $<2.9$ & 1.96 & 11 & & & STD-NMR & $\begin{array}{l}\text { Interface between } \\
\text { protein dimers (no } \\
\text { functional effect) }\end{array}$ \\
\hline
\end{tabular}




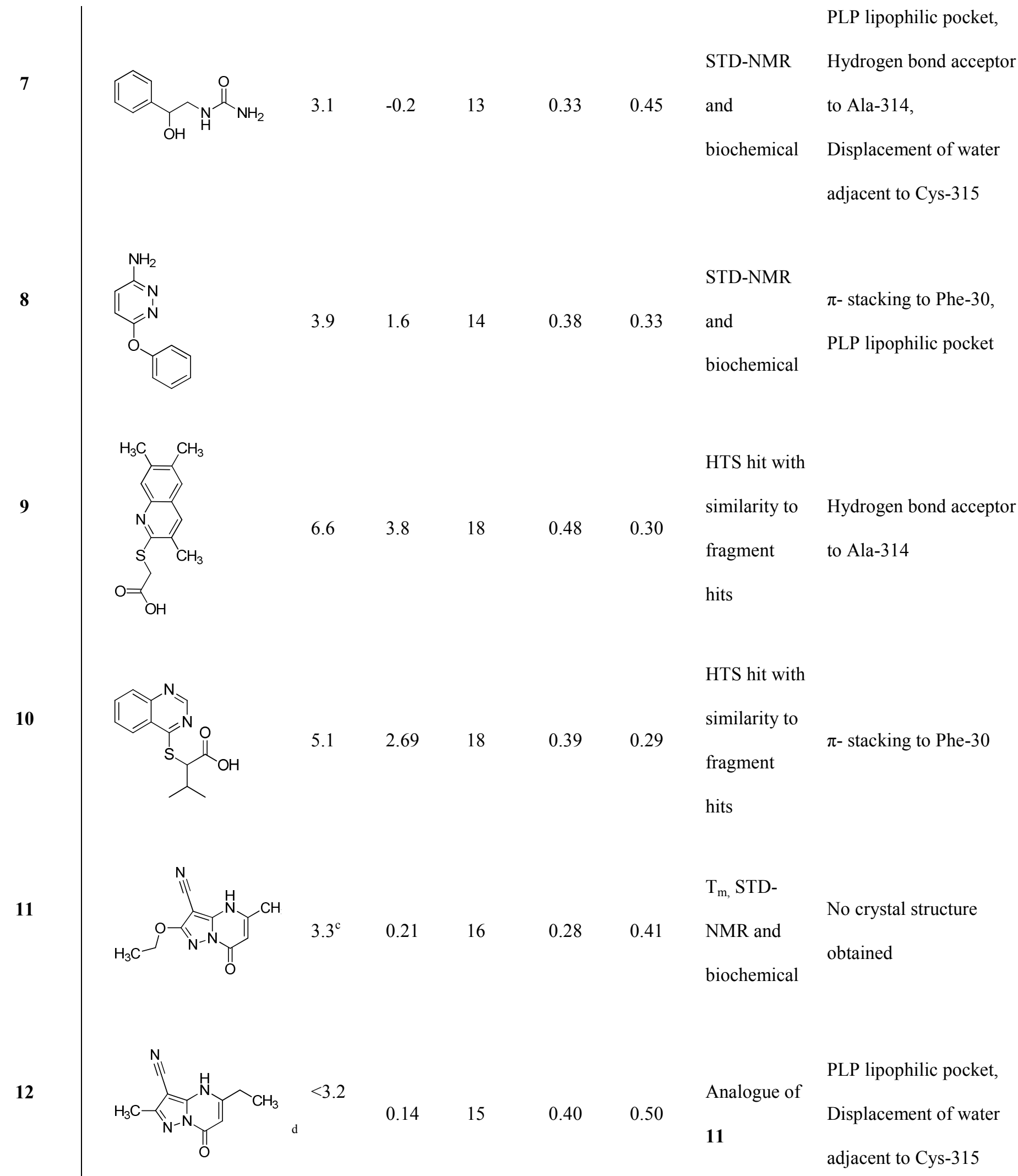


<smiles>N#Cc1cnn2c(=O)cc(Cc3ccccc3)[nH]c12</smiles>

$$
4.6
$$

0.77

19

0.44

0.45

Analogue of

PLP lipophilic pocket,

11

Displacement of water adjacent to Cys-315

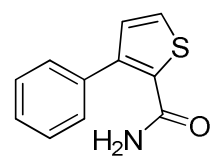

$$
\mathrm{T}_{\mathrm{m},} \text { STD- }
$$

NMR and biochemical

No crystal structure obtained

PLP lipophilic pocket, Analogue of Hydrogen bond acceptor 14 to Ala-314

Table 1 Summary of fragment hits identified. ${ }^{\mathrm{a}}$ compound reported inactive $\left(\mathrm{pIC}_{50}<4.2\right)$ on 3 out of 35 test occasions; ${ }^{b}$ compound reported inactive $\left(\mathrm{pIC}_{50}<2.9\right)$ on 1 out of 2 test occasions; ${ }^{\mathrm{c}}$ compound reported inactive $\left(\mathrm{pIC}_{50}<2.9\right)$ on 1 out of 3 test occasions; ${ }^{\mathrm{d}}$ compound reported inactive $\left(\mathrm{pIC}_{50}<3.2\right)$ on 2 out of 4 test occasions.

Table 1 summarises the fragment hits identified which yielded liganded crystal structures, along with their calculated ligand efficiency (LE) ${ }^{16}$ and modified lipophilic ligand efficiency (LLE ${ }_{\mathrm{AT}}$ ) as defined by researchers at Astex. ${ }^{17}$ The crystal structures obtained for the hits, showed occupation of a range of positions in the BCATm binding site, and that significant movement in the protein was induced by the compounds. Some of the most important features for binding are summarised in the X-ray crystal structures shown in Figure 3. 

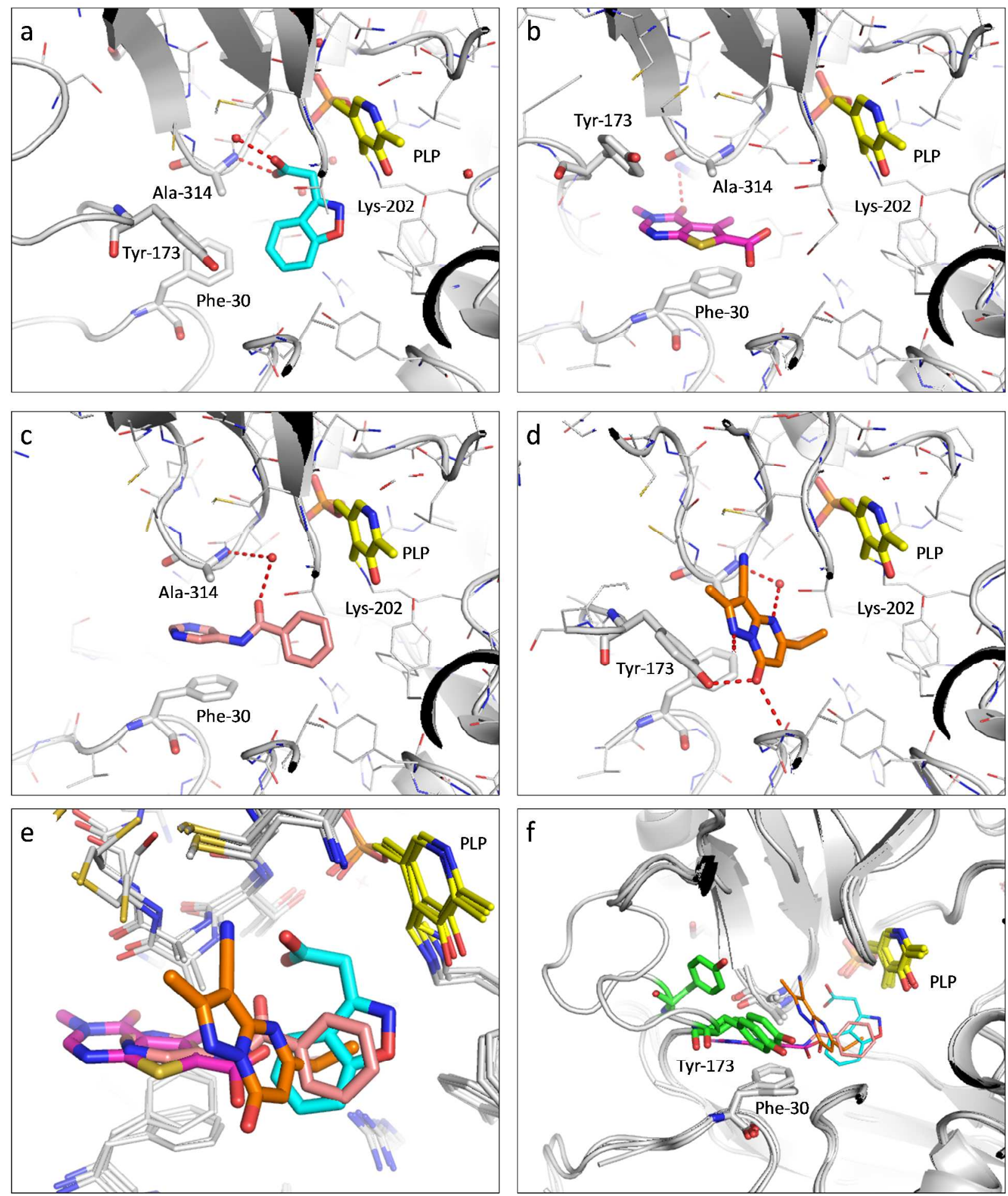

Figure 3: X-ray crystal structures of compounds 1(cyan, PDB entry 5I5S), 4(magenta PDB entry 5I5V), 5(pink PDB entry 5I5W) and 12(orange PDB entry 5BWT ${ }^{4}$ ) in the 
BCATm binding site in panels a, b, $c$ and d respectively. Panel e shows an overlay of all these compounds within the binding site. Panel f shows the same overlay but with Tyr-173 in green stick format, highlighting the mobility of the 170-180 loop region.

Benzo $[d]$ isoxazole 1 (Figure 3a) occupied a binding pocket defined by a lipophilic region adjacent to the PLP cofactor, which is confined by a closed 'gate' between residues Phe-30 and Tyr-173. The carboxylic acid carbonyl group acted as a hydrogen bond acceptor to the backbone NH of Ala-314.

The crystal structure of thienopyrimidine 4 (Figure 3b) showed occupation of a distinct binding site. The site adjacent to the cofactor was occupied only by ethylene glycol (present in crystallography medium) and the Phe-30 Tyr-173 'gate' had opened to allow the formation of a $\pi$-stacking interaction between Phe-30 and the heterocyclic core. The opening of the gate involved significant conformational rearrangement, with Phe-30 moving by around $2 \AA$, whilst Tyr-173 moved by approximately $6 \AA$. Additionally, the amide carbonyl acted as a hydrogen bond acceptor to a lysine NH (Lys-79).

The pyrimidine ring of the biaryl amide 5 (Figure 3c) formed a similar $\pi$-stacking interaction with Phe-30 to thienopyrimidine 4, whilst the phenyl ring occupied a similar lipophilic aromatic pocket to benzo[d]isoxazole 1 . The tyrosine residue, which moved to open the induced pocket in the structure of 4 (Tyr-173) was completely disordered in this structure. There are no direct hydrogen bonding interactions between the heteroatoms of the fragment and the protein, which may explain the poor ligand efficiency observed. However the amide carbonyl is well solvated and there is a water mediated hydrogen bond to the hydroxyl of Tyr-141. Biaryl amide 5 was an 
effective bridge between the two binding sites identified, and demonstrated that it is possible to have both sites occupied simultaneously.

Pyrazolopyrimidine 12 (Figure 3d PDB entry 5BWT ${ }^{4}$ ) displayed an additional distinct binding mode. The pendant ethyl group was close to the lipophilic site occupied by aromatic groups for compounds $\mathbf{1}$ and 5, and the 'gate' was closed. The heterocyclic core was positioned in a site which was unoccupied in the other structures, with the nitrile substituent displacing a water molecule, which formed a hydrogen bonding interaction with the $\mathrm{NH}$ of Cys-315 in other structures. The pyridone carbonyl forms hydrogen bonds with Tyr-173 and the backbone of Val155. The pyridone $\mathrm{NH}$ and pyrazole $\mathrm{N}$ are both involved in water networks.

When all of these liganded crystal structures of the fragment hits were considered together (Figure 3e and f), it was clear that the BCATm protein has considerable flexibility to accommodate a range of ligand binding modes. However, there were several binding 'hot-spots' identified, which appeared to act as anchors for the fragments. The most notable of these was the lipophilic pocket adjacent to the PLP, hydrogen bonding with Ala-314, $\pi$-stacking with Phe-30 and displacement of the water molecule adjacent to Cys-315. All of the hits identified satisfied at least one of these interactions (see Table 1). This flexibility in the protein would thus have caused difficulties in attempting to predict the binding modes of hits using docking methods alone. Therefore, to enable structure based fragment growth, it was important to generate multiple X-ray crystal structures (as is common practice), even for compounds which appeared to be closely structurally related. The diversity of structural information obtained provided opportunities to grow the fragment hits in various ways ${ }^{18}$.

\section{Hits to Leads Optimisation}


The fragment hits identified were grouped ("clustered") according to their binding modes in the BCATm active site. An example of this process is shown for compounds $\mathbf{1 , 2}$ and $\mathbf{3}$, which look dissimilar on the basis of their chemical structures, but which all make similar binding interactions with the protein (Figure 4). One exemplar was chosen from each vectorial cluster, either because it demonstrated superior efficiency of binding, or because it offered more flexible and tractable chemistry than other structures within the same cluster. The fragment growth and further optimisation of the pyrazolopyrimidinone series represented by compounds $\mathbf{1 1 - 1 3}$ is described in the complementary paper; ${ }^{4}$ a noteworthy feature of this series was that the original fragment hit (11) did not give a crystal structure, but analogue searching identified closely related compounds that did yield liganded crystal structures. Herein, the initial lead optimisation efforts on two other series to illustrate the strategies employed are described.

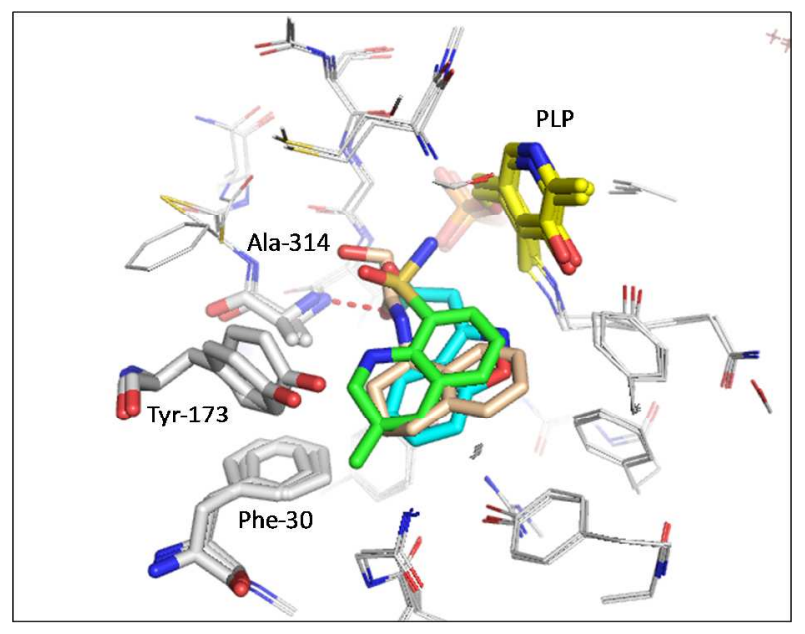

Figure 4: Example of vectorial clustering, showing an overlay of compounds 1 (cyan PDB entry 5I5S), 2(green PDB entry 5I5T) and 3(beige PDB entry 5I5U) with similar binding interactions. 


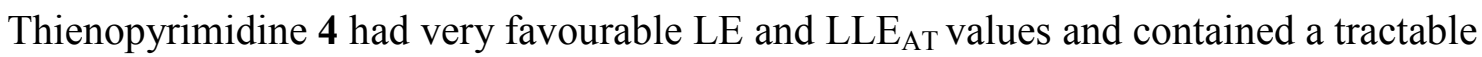
functional group (carboxylic acid), which could be used to grow towards the PLP pocket. The crystal structure of biaryl amide $\mathbf{5}$ provided further confidence in this approach because it showed that concomitant binding in both of these pockets could be achieved. With these aims in mind, initial optimisation focussed on a small array of amides, mostly containing lipophilic substituents, which were designed to fill the PLP pocket.

These compounds were synthesised using HATU-mediated coupling chemistry or via acylation using the appropriate acid chloride (Table 2). Due to monomer availability, some of the chemistry was carried out on the closely related des-methyl series e.g. 16, which showed similar activity to the initial hit $\mathbf{4}$. Analogues $\mathbf{1 7}$ and $\mathbf{1 8}$ confirmed that activity with either of these two substituents was comparable. In general, aromatic amides were preferred to aliphatic substituents, as demonstrated by the comparisons between compounds $\mathbf{1 7}$ and $\mathbf{1 8}$ plus $\mathbf{1 9}$ and 20. Substitution on the pendant phenyl ring was only tolerated in the ortho position (compounds $\mathbf{2 1}$, 22, 23). Attempts to accommodate heteroaromatic rings in the lipophilic pocket were not productive (e.g. compounds $\mathbf{2 4}$ and $\mathbf{2 5}$ ), with the exceptions of the lipophilic thiophene (26) and

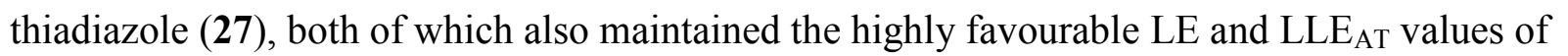
the hit. 

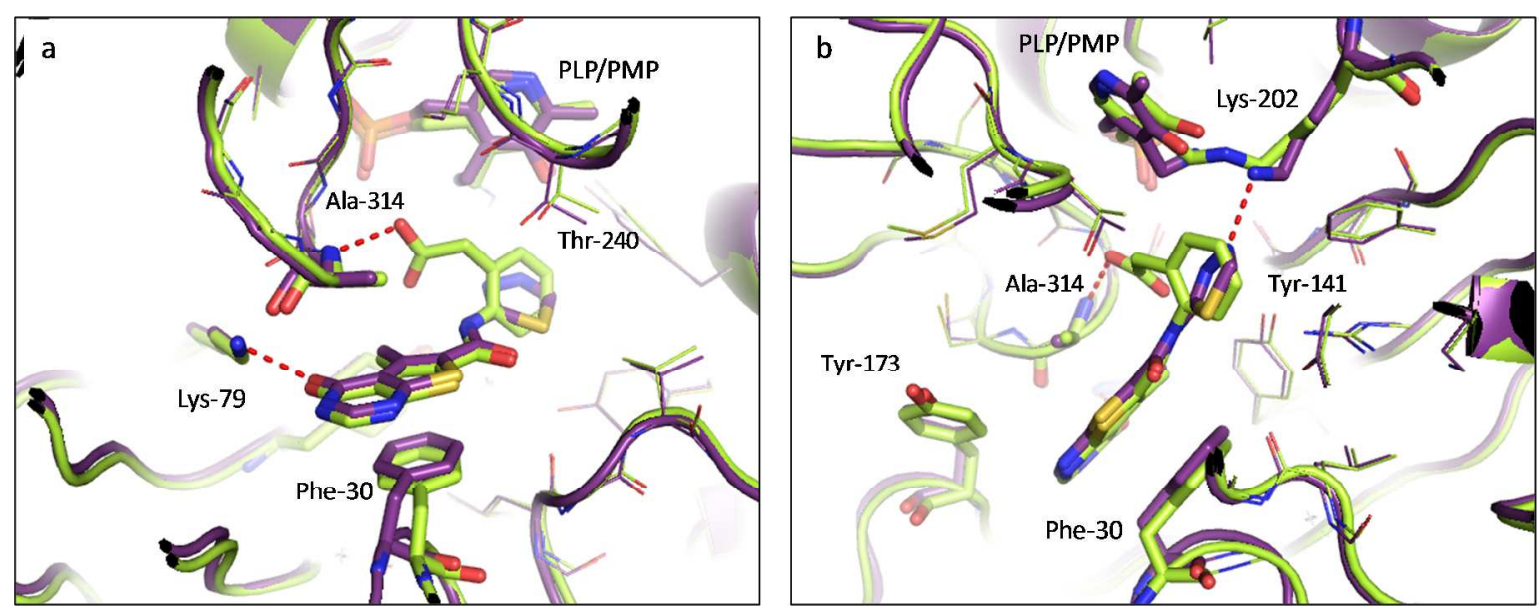

Figure 5: Overlay of compounds 27 (purple PDB entry 5I5X) and 29 (pale green PDB entry

5I5Y). Panel a. shows the common interactions with Lys-79, Phe-30 and Ala-314. Panel b.

\section{illustrates the difference in interactions around PLP/PMP for the two compounds}

The potency associated with compound $\mathbf{2 7}$ could not be rationalised by knowledge of the crystal structure of compound 4 . Soaking experiments failed to produce a crystal structure of compound 27, however co-crystallisation was successful, which yielded the first liganded structure of BCATm in the PMP form (Figure 5). The PMP form shows a few significant differences with respect to the PLP form. Firstly, the Lys-202 sidechain, now no longer covalently linked to cofactor, as in the PLP form, is free to shift slightly to optimally interact with one of the nitrogen atoms in the thiadiazole ring. Secondly, the PMP cofactor pyridine rotates by $\sim 11^{\circ}$ from the PLP pyridine plane and Leu-266 adopts a lower energy rotamer conformation due to the additional space created by the rotation of the PMP pyridine ring. Due to its potent inhibition of BCATm, compound 27 was progressed to a cellular assay measuring BCATm inhibition, and was found to have a cellular $\mathrm{pIC}_{50}$ value of 5.4. 


1
2
3
4
5
6
7
8
9
10
11
12
13
14
15
16
17
18
19
20
21
22
23
24
25
26
27
28
29
30
31
32
33
34
35
36
37
38
39
40
41
42
43
44
45
46
47
50
58
59
50
52
53
50<smiles>[R]C(=O)c1sc2ncn([R])c(=O)c2c1C</smiles>

\begin{tabular}{|c|c|c|c|c|c|}
\hline $\begin{array}{l}\text { Compound } \\
\text { Number }\end{array}$ & $\mathrm{R} 1$ & $\mathrm{R} 2$ & $\mathrm{pIC}_{50}$ & LE & $\operatorname{LLE}_{\mathbf{A T}}$ \\
\hline 4 & $\mathrm{CH}_{3}$ & $\mathrm{OH}$ & $4.2^{\mathrm{a}}$ & 0.38 & 0.44 \\
\hline 16 & $\mathrm{H}$ & $\mathrm{OH}$ & 4.3 & 0.44 & 0.51 \\
\hline 17 & $\mathrm{CH}_{3}$ & & 5.1 & 0.33 & 0.34 \\
\hline 18 & $\mathrm{H}$ & & 5.1 & 0.36 & 0.37 \\
\hline 19 & $\mathrm{CH}_{3}$ & & $<4.2$ & & \\
\hline 20 & $\mathrm{CH}_{3}$ & & $<3.2$ & & \\
\hline 21 & $\mathrm{H}$ & & $4.3^{b}$ & 0.28 & 0.30 \\
\hline
\end{tabular}


$\mathrm{H}$

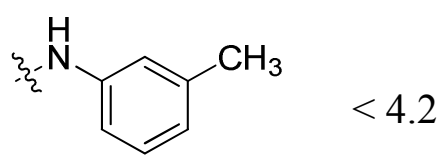

23

$\mathrm{H}$

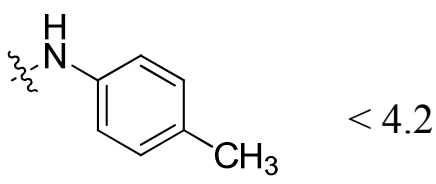

$\mathrm{H}$<smiles>Nc1cccnc1</smiles>

3.6

$0.25 \quad 0.33$

25

$\mathrm{H}$<smiles>[As]c1ccon1</smiles>

$\mathrm{H}$<smiles>[Te]Nc1cccs1</smiles>

5.8

0.48

0.45

27<smiles>[14CH3]Nc1nncs1</smiles>

6.7

0.48

0.63

\section{Table 2: Activity and efficiency data for amide analogues of compound 4.}

${ }^{a}$ compound reported inactive $\left(\mathrm{pIC}_{50}<4.2\right)$ on 3 out of 35 test occasions; ${ }^{b}$ compound reported inactive $\left(\mathrm{pIC}_{50}<4.2\right)$ on 2 out of 4 test occasions.

The next logical expansion was to grow towards Ala-314 to try to exploit a hydrogen-bonding opportunity, which had been identified from the fragment screening as a binding hot-spot. A 
range of heteroatom-containing functional groups were introduced in the ortho-position of compound 18 (Table ). From this effort, only the aryl acetate 29 showed any significant improvement in BCATm inhibition resulting in micromolar activity, whilst maintaining good efficiencies. Crystallisation of this compound in BCATm (Figure 5) confirmed that the acid carbonyl moiety was acting as a hydrogen bond acceptor to the backbone NH of Ala-314.<smiles>[R]c1ccccc1NC(=O)c1sc2nc[nH]c(=O)c2c1C</smiles>

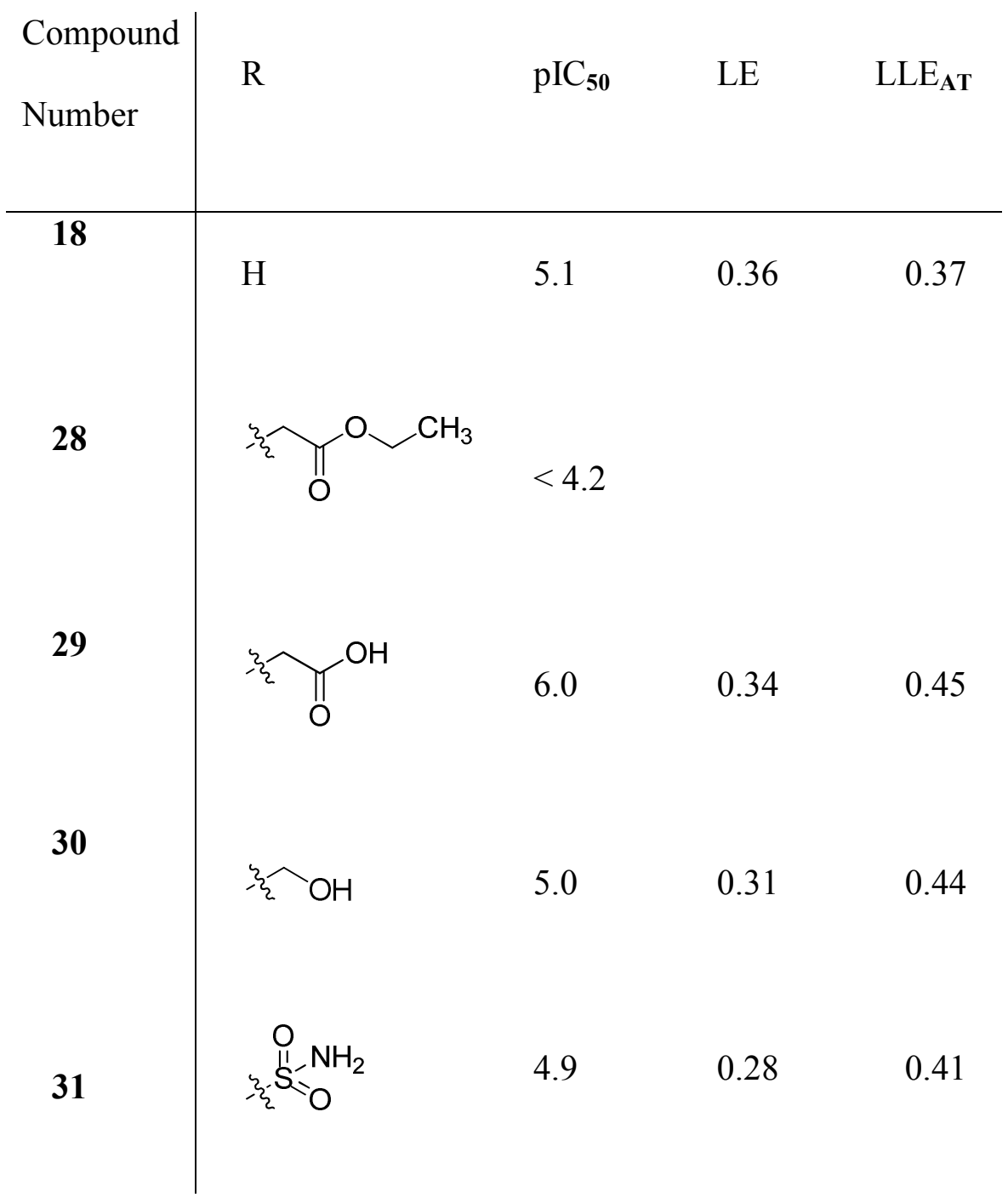




\section{Table 3: Results of targeting Ala-314 through growth from the ortho-position of 18}

By using the structural information obtained from different fragment hits to identify binding hot spots it was thus possible to grow weakly active fragment $\mathbf{4}$ into more potent analogues, with activity in a cellular assay.

Analysis of structures showed that biaryl amide $\mathbf{5}$ offered potential vectors towards the Ala$314 \mathrm{NH}$ donor and the Lys-79 $\mathrm{NH}_{2}$ donor, to which the pyrimidinone carbonyl of 4 was hydrogen bonded. The biaryl amide substructure is an abundant motif in the GSK compound collection, so the initial SAR was readily delineated (Table 4).

\begin{tabular}{l|llllll} 
Compound & $\mathrm{pIC}_{50}$ & $\mathrm{LE}$ & $\mathrm{LLE}_{\mathrm{AT}}$ & clogP \\
\hline 5 & & 3.0 & 0.27 & 0.26 & 1.31 \\
\hline 33
\end{tabular}


<smiles>CS(=O)(=O)c1ccccc1C(=O)Nc1ccccc1</smiles>
3.7
0.27
0.26
1.66<smiles>CC=CNCc1ccccc1</smiles>

$3.5^{\mathrm{a}}$

0.25

$0.25 \quad 1.58$

36<smiles>NC(=O)c1ccc(NC(=O)c2ccc(Cl)c(Cl)c2)cc1</smiles>

5.6

0.39

0.31

2.86

37<smiles>O=C(Nc1ccc(-c2cc[nH]n2)cc1)c1ccccc1</smiles>

\section{3}

0.36

0.26

3.00

38<smiles>O=C(O)Cc1ccccc1C(=O)Nc1ccc(-c2cc[nH]n2)cc1</smiles>

5.7

0.33

0.32

1.94

Table 4: Screening results from analogues of 5 available in the GSK collection.

${ }^{\mathrm{a}}$ compound reported inactive $\left(\mathrm{pIC}_{50}<4.2\right)$ on 2 out of 4 test occasions. 
The pyrimidine ring was initially replaced with phenyl, as a greater number of analogues were available, and the crystal structure of 5 suggested that the pyrimidine nitrogens were not participating in any binding interactions. As with the optimisation of $\mathbf{4}$, it was found that adding hydrogen bond acceptors, which could interact with Ala-314, provided modest improvements in binding (34 and 35), with maintained ligand efficiency. A more dramatic improvement in enzyme inhibition was achieved when hydrogen bond acceptors, represented by carboxamide and pyrazole (36 and 37), enabled engagement with Lys-79. Carboxamide 36 also had additional lipophilic chlorine groups that enhanced binding in the PLP pocket, contributing to micromolar levels of activity, which represented a roughly 1000-fold increase in activity from the fragment hit. This compound also displayed a significant improvement in the efficiency measures relative to the hit compound 5. Synthesis of compound 38, which combined the acceptors targeting both Lys-79 and Ala-314 demonstrated that the effects on the activity could be additive, with good LE and LLE $_{\mathrm{AT}}$ values achieved. The intent of this design was confirmed by the Xray structure of $\mathbf{3 8}$ within BCATm shown in Figure 6.

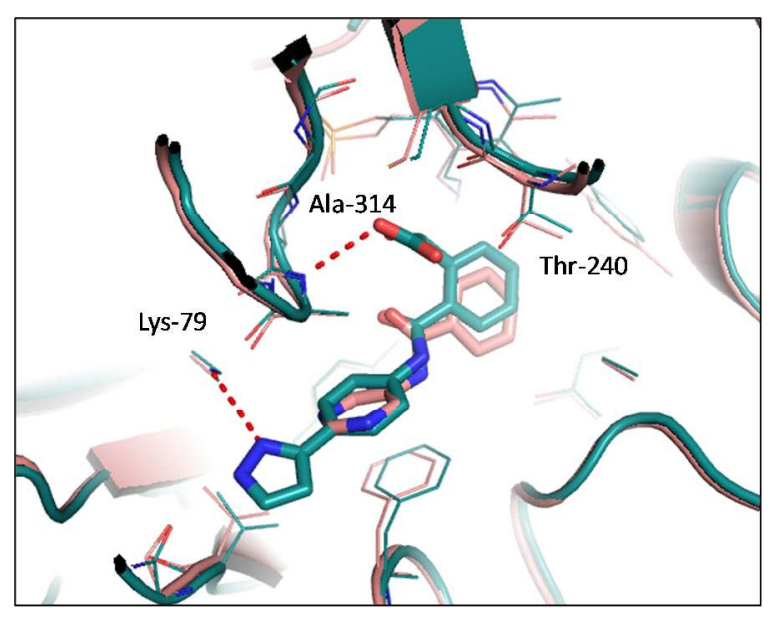

Figure 6: Overlay of compounds 38 (blue PDB entry 5I60) and 5 (pink PDB entry 5I5W) confirms 38 makes additional interactions with Lys-79 and Ala-314. 
Once a good understanding of the SAR within this series had been established through screening of available analogues, attention was turned to improving the physicochemical profiles of the compounds. Biaryl amides are notoriously insoluble, being highly planar and crystalline, ${ }^{19}$ and indeed, the measured solubilities of these compounds were poor (Table, compounds $\mathbf{3 7}$ and 39). Two strategies were adopted to improve the solubility within the series. The amide N-H was constrained in a tetrahydroisoquinoline ring to prevent intermolecular hydrogen bonding, which could contribute to the high crystallinity (40 and 42). Additionally, the pyrimidine ring from the initial hit was returned to the molecules in place of the phenyl ring to lower the lipophilicity (compound 41). The targeted analogues were synthesised as shown in Scheme 2. Both of these strategies resulted in a modest improvement in enzyme inhibition and approximately 10 -fold increased solubility. As in the optimisation of thienopyrimidine 4, the biaryl amide series had been grown into a series of lead-like molecules through focussed structure-based design combined with consideration of molecular properties.

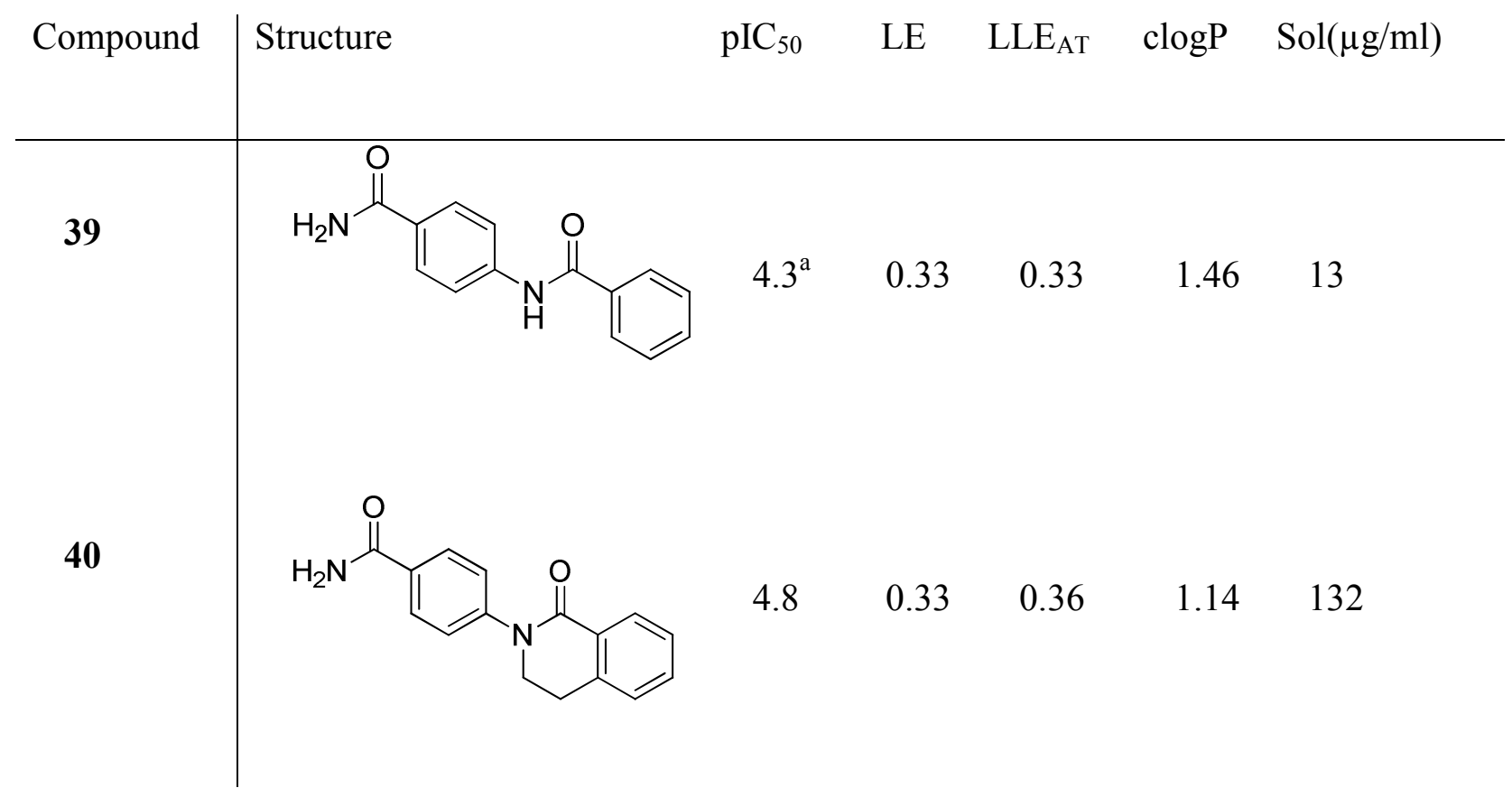


1

2

3

4

5

6

7

8

9

10

11

12

13

14

15

16

17

18

19

20

21

22

23

24

25

26

27

28

29

30

31

32

33

34

35

36

37

38

39

40

41

42

43

44

45

46

47

48

49

50

51

52

53

54

55

56

57

58

59

60
37<smiles>O=C(Nc1ccc(-c2cc[nH]n2)cc1)c1ccccc1</smiles>

$\begin{array}{llll}5.2 & 0.36 & 0.26 & 3.00\end{array}$

12

$\begin{array}{lllll}5.5 & 0.38 & 0.35 & 1.94 & 82\end{array}$

$\begin{array}{lllll}5.8 & 0.36 & 0.29 & 2.83 & 94\end{array}$

Table 5: Data from the biaryl amides series, illustrating structural modifications

designed to improve solubility. ${ }^{a}$ compound reported inactive $\left(\mathrm{pIC}_{50}<4.2\right)$ on 1 out of 4 test occasions 

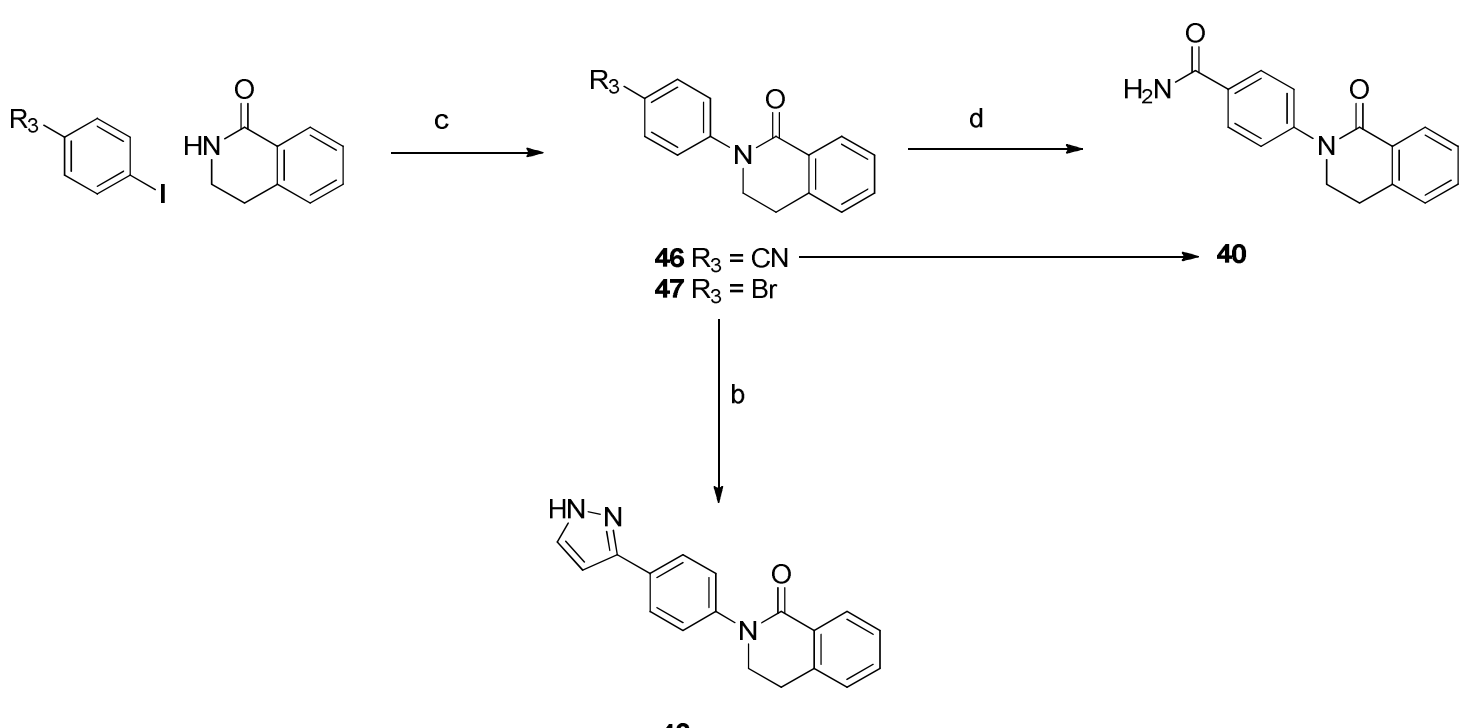

42

Reagents and conditions: (a) HATU, DIPEA, DMF, $20-40{ }^{\circ} \mathrm{C}, 41-79 \%$; (b) $1 H$-pyrazol-3ylboronic acid, $\mathrm{Pd}\left(\mathrm{PPh}_{3}\right)_{4}, \mathrm{Na}_{2} \mathrm{CO}_{3}$ (sat. aq.), $130{ }^{\circ} \mathrm{C}$, microwave $20 \mathrm{~min} .41-72 \%$; (c) CuI, $\mathrm{K}_{2} \mathrm{CO}_{3}$, DMF, $160{ }^{\circ} \mathrm{C}, 18 \mathrm{~h}, 57-66 \%$; (d) $2 \mathrm{M} \mathrm{NaOH}$ (aq.), $30 \% \mathrm{H}_{2} \mathrm{O}_{2}$ (aq.), EtOH, $50{ }^{\circ} \mathrm{C}, 20 \mathrm{~h}$, $19 \%$.

\section{Scheme 2: Synthesis of analogues of compound 5}

\section{Conclusions}

When carrying out any diversity screening campaign, but particularly when utilising fragmentbased approaches, it is important to realise that different biochemical and biophysical screening techniques can, and indeed do, identify different sub-sets of hits. Therefore, there could be an 
advantage to using multiple, complementary techniques for the initial screening phase. This is particularly important in FBDD, where the binding of hits will likely to be near to the limit of detection in some assays. This set of hits identified for BCATm, and the crystal structures generated have illustrated many aspects of the binding of small molecules to this enzyme for the first time. It was particularly interesting to observe such different conformations of the protein between different fragment hits, whilst gratifying to be able to identify several binding 'hot spots' in the protein structure and confirm that these could be accessed simultaneously and from different structural types. The insights from multiple liganded crystal structures during both the screening and chemical optimisation stages were invaluable in guiding progress, consistent with contemporary practice ${ }^{11,20}$ in fragment based design. Another important aspect of this work was the use of analogue searching from an extensive collection. This was important both in the hit finding phase, where it was used to generate additional hits, and in fragment optimisation and growth, where significant improvements in hit activities were obtained without recourse to synthesis. The chemical libraries are a major asset for large pharmaceutical companies, which allow scientists to rapidly explore SAR around fragment hits. The "SAR by catalogue" allowed expansion beyond the deliberately designed screening sets, whilst continuing to exercise discipline with the molecular properties of compounds screened. Finally, micromolar inhibitors of BCATm have been identified, with characterised novel binding modes and measurable activities in a cellular assay. This represents a major step forward towards the goal of establishing if pharmaceutical inhibition of BCATm using small molecules could provide a useful treatment for metabolic diseases; the accompanying paper $^{4}$ describes further progress achieved in one series.

\section{Experimental}




\section{Chemistry}

All solvents and reagents, unless otherwise stated, were commercially available from regular suppliers such as Sigma-Aldrich and Fluorochem and were used as purchased without further purification. Nuclear magnetic resonance $\left({ }^{1} \mathrm{H}\right.$ NMR and ${ }^{13} \mathrm{C}$ NMR) spectra were recorded on a Bruker AVI (400 MHz), Bruker Nano (500 MHz) or Bruker AVII+ (600 MHz) spectrometer (with cryoprobe) in the indicated solvent. Chemical shifts $\delta$ are reported in parts per million (ppm) relative to tetramethylsilane and are internally referenced to the residual solvent peak. Coupling constants $(J)$ are given in Hertz $(\mathrm{Hz})$ to the nearest $0.5 \mathrm{~Hz}$. Liquid Chromatography Mass Spectroscopy (LCMS) analysis was conducted on either System A, a Waters Acquity UPLC BEH $\mathrm{C}_{18}$ column (50 mm x $2.1 \mathrm{~mm}$ i.d. $1.7 \mu \mathrm{m}$ packing diameter) at $40{ }^{\circ} \mathrm{C}$ eluting with $0.1 \% \mathrm{v} / \mathrm{v}$ solution of formic acid in water (solvent $\mathrm{A}$ ) and $0.1 \% \mathrm{v} / \mathrm{v}$ solution of formic acid in acetonitrile (solvent B), using the following elution gradient $0.0-1.5 \mathrm{~min} 3-100 \% \mathrm{~B}, 1.5-1.9 \mathrm{~min}$ $100 \% \mathrm{~B}, 1.9-2.0 \mathrm{~min} 3 \% \mathrm{~B}$, at a flow rate of $1 \mathrm{~mL} / \mathrm{min}$; or System B, a Waters Acquity UPLC $\mathrm{BEH} \mathrm{C}_{18}$ column $(50 \mathrm{~mm} \times 2.1 \mathrm{~mm}$ i.d. $1.7 \mu \mathrm{m}$ packing diameter $)$ at $40{ }^{\circ} \mathrm{C}$ eluting with $10 \mathrm{mM}$ ammonium bicarbonate in water adjusted to $\mathrm{pH} 10$ with ammonia solution (solvent $\mathrm{A}$ ) and acetonitrile (solvent B), using the following elution gradient $0.0-1.5 \mathrm{~min} 1-97 \% \mathrm{~B}, 1.5-1.9 \mathrm{~min}$ $97 \% \mathrm{~B}, 1.9-2.0 \mathrm{~min} 100 \% \mathrm{~B}$, at a flow rate of $1 \mathrm{~mL} / \mathrm{min}$. The UV detection was based on an average signal from wavelength of $210 \mathrm{~nm}$ to $350 \mathrm{~nm}$. The mass spectra were recorded on a Waters ZQ mass spectrometer using alternate-scan positive and negative mode electrospray ionisation. Preparative HPLC using a Mass Directed Auto Purification (MDAP) were conducted on a Waters FractionLynx system comprising of a Waters 515 pump with extended pump heads, Waters 2767 auto sampler, Waters 996 photodiode array detector and Gilson 202 fraction collector on an XBridge or Sunfire C18 column (30 mm x $150 \mathrm{~mm}$ i.d. $5 \mu \mathrm{m}$ packing diameter) at 
ambient temperature. The mobile phase was $0.1 \% \mathrm{v} / \mathrm{v}$ solution formic acid in water or $10 \mathrm{mM}$ ammonium bicarbonate in water adjusted to $\mathrm{pH} 10$ with ammonia solution (solvent $\mathrm{A}$ ) and $0.1 \%$ v/v solution formic acid in acetonitrile or acetonitrile (solvent B). The UV detection is a summed signal from wavelength of $210 \mathrm{~nm}$ to $350 \mathrm{~nm}$. The mass spectra were recorded on Waters ZQ mass spectrometer using alternate-scan positive and negative electrospray ionisation. The software used was MassLynx 3.5 with OpenLynx and FractionLynx options. High resolution mass spectra (HRMS) were obtained on a Micromass Q-Tof Ultima hybrid quadrupole time-offlight mass spectrometer, equipped with a Z-spray interface (ESI), over a mass range of 100 $1100 \mathrm{Da}$, with a scan time of $0.9 \mathrm{~s}$ and an interscan delay of $0.1 \mathrm{~s}$. Reserpine was used as the external mass calibrant $\left([\mathrm{M}+\mathrm{H}]^{+}=609.2812 \mathrm{Da}\right)$. The Q-Tof Ultima mass spectrometer was operated in W reflectron mode to give a resolution (FWHM) of 16000-20000. Ionisation was achieved with a spray voltage of $3.2 \mathrm{kV}$, a cone voltage of $50 \mathrm{~V}$, with cone and desolvation gas flows of 10-20 and $600 \mathrm{~L} / \mathrm{hr}$, respectively. The source block and desolvation temperatures were maintained at $120^{\circ} \mathrm{C}$ and $250^{\circ} \mathrm{C}$ respectively. The elemental composition was calculated using MassLynx v4.1 for the $[\mathrm{M}+\mathrm{H}]^{+}$and the mass error quoted as ppm. Flash column chromatography was conducted on a Combiflash ${ }^{\circledR}$ Rf, automated flash chromatography system (Teledyne Isco) using disposable normal or reverse phase Redisep cartridges ( $4 \mathrm{~g}$ to $330 \mathrm{~g}$ ). The CombiFlash ${ }^{\circledR}$ Rf used RFID (Radio Frequency Identification Detector) technology to automate setting the parameters for purification runs and fraction collection. The system was equipped with a UV variable dual-wavelength and a Foxy ${ }^{\circledR}$ fraction collector enabling automated peak cutting, collection and tracking. The purity of all compounds screened in the biological assays was examined by LCMS analysis and was found to be $\geq 95 \%$ unless otherwise specified. The human 
biological samples were sourced ethically and their research use was in accord with the terms of the informed consents.

Compounds 2, 3, and 14 were purchased from Enamine. Compound 12 was purchased from Vitas. Compound 18 was purchased from ChemDiv. Compounds $\mathbf{1 , ~ 4 , ~ 5 , ~ 6 , ~ 7 , ~ 8 , ~ 1 0 , ~ 1 3 , ~ 1 5 , ~ 3 3 , ~}$ and 34 were obtained from the GSK compound collection, but are also available from commercial suppliers. Compound $\mathbf{3 5}$ was obtained from the GSK compound collection and may be synthesised according to the procedure described by Azizian and co-workers. ${ }^{21}$

\section{2-Ethoxy-5-methyl-7-oxo-4,7-dihydropyrazolo[1,5-a]pyrimidine-3-carbonitrile (11) was} obtained from the GSK compound collection. ${ }^{1} \mathrm{H}$ NMR $\left(500 \mathrm{MHz}, \mathrm{DMSO}-\mathrm{d}_{6}\right) \delta \mathrm{ppm} 5.78$ (s, 1 H), $4.36(\mathrm{q}, J=7.0 \mathrm{~Hz}, 2 \mathrm{H}), 2.47-2.52(\mathrm{~m}, 1 \mathrm{H}), 2.27(\mathrm{~s}, 3 \mathrm{H}) .1 .36(\mathrm{t}, J=7.0 \mathrm{~Hz}, 3 \mathrm{H})$; LCMS (ESI, formic) $m / z 219.01[\mathrm{M}+\mathrm{H}]^{+}, \mathrm{R}_{\mathrm{t}}=0.63 \mathrm{~min}$.

\section{5-methyl-4-oxo-3,4-dihydrothieno[2,3-d]pyrimidine-6-carboxylic acid (16). Lithium}

hydroxide, monohydrate $(2.3 \mathrm{~g}, 55 \mathrm{mmol})$ was added to a solution of ethyl 5-methyl-4-oxo-3,4dihydrothieno[2,3- $d]$ pyrimidine-6-carboxylate $(4.0 \mathrm{~g}, 17 \mathrm{mmol})$ in a mixture of THF $(50 \mathrm{~mL})$, $\mathrm{MeOH}(25 \mathrm{~mL})$ and water $(8 \mathrm{~mL})$. The reaction mixture was stirred at room temperature for 16 h. Lithium hydroxide, monohydrate $(1.0 \mathrm{~g}, 24 \mathrm{mmol})$ was added and the reaction mixture was stirred for another $6 \mathrm{~h}$. The reaction mixture was then heated at $40{ }^{\circ} \mathrm{C}$ for $24 \mathrm{~h}$. Solvent was evaporated under reduced pressure. The resulting crude product was dissolved in water and the mixture was acidified to $\mathrm{pH} 1$ with $2 \mathrm{M}$ aqueous $\mathrm{HCl}$ solution. The resulting precipitate was collected by filtration and dried in a vacuum oven overnight to give the title product as a pale pink solid (3.5 g, $99 \%$ ). ${ }^{1} \mathrm{H}$ NMR (400 MHz, DMSO-d 6 ) $\delta 13.31$ (br. s, 1H), 12.56 (br. s, 1H), 
$8.17(\mathrm{~s}, 1 \mathrm{H}), 2.80(\mathrm{~s}, 3 \mathrm{H})$; LCMS (ESI, formic) $\mathrm{m} / \mathrm{z} 211.02[\mathrm{M}+\mathrm{H}]^{+}, \mathrm{R}_{\mathrm{t}}=0.45 \mathrm{~min}$; HRMS (ESI) calcd for $\mathrm{C}_{8} \mathrm{H}_{6} \mathrm{~N}_{2} \mathrm{O}_{3} \mathrm{~S}+\mathrm{H}^{+}$211.0177, found 211.0172 (2.95 min).

\section{General procedure A for amide coupling}

The appropriate amine (1.2 eq), HATU (1.2 eq) and DIPEA (2 eq) were added to a solution of 3,5-dimethyl-4-oxo-3,4-dihydrothieno[2,3-d]pyrimidine-6-carboxylic acid (4) (1 eq) in DMF (4 $10 \mathrm{~mL}$ ). The mixture was stirred at room temperature until reaction was complete by LCMS. Water $(50 \mathrm{~mL})$ and EtOAc $(50 \mathrm{~mL})$ were added. The aqueous phase was extracted with EtOAc $(2 \times 50 \mathrm{~mL})$. The organic layers were combined, passed through a hydrophobic frit and concentrated to dryness under reduced pressure. The resulting crude product was purified by reverse phase chromatography to give the desired final product.

\section{General procedure B for amide coupling}

HATU (1.2 eq) and DIPEA (2 eq) were added to a solution of 5-methyl-4-oxo-3,4dihydrothieno[2,3-d]pyrimidine-6-carboxylic acid (16) (1 eq) in DMF (1.5-2.5 mL). The mixture was stirred at room temperature between 1 to $10 \mathrm{~min}$. The appropriate amine (1.2 eq) was then added and the reaction mixture was stirred at room temperature until reaction was complete by LCMS. Solvent was then evaporated under reduced pressure. The resulting crude product was purified by reverse phase chromatography to give the desired final product.

\section{3,5-dimethyl-4-oxo-N-phenyl-3,4-dihydrothieno[2,3-d]pyrimidine-6-carboxamide (17) was}

prepared according to general procedure A using aniline $(50 \mu \mathrm{L}, 0.54 \mathrm{mmol})$. The resulting crude product was purified by reverse phase chromatography using the formic acid MDAP (gradient B over $15 \mathrm{~min}$ ) to give the title product as white solid (90 mg, $64 \%) .{ }^{1} \mathrm{H}$ NMR (400 MHz, DMSO- 
$\left.\mathrm{d}_{6}\right) \delta 10.25(\mathrm{~s}, 1 \mathrm{H}), 8.50(\mathrm{~s}, 1 \mathrm{H}), 7.68$ (br. d, $\left.J=7.5 \mathrm{~Hz}, 2 \mathrm{H}\right), 7.36$ (br. t, $\left.J=8.0 \mathrm{~Hz}, 2 \mathrm{H}\right), 7.07$ -

7.16 (br. t, $J=7.5 \mathrm{~Hz}, 1 \mathrm{H}), 3.49$ (s, 3H), 2.74 (s, 3H); LCMS (ESI, high pH) $m / z 300.04$

$[\mathrm{M}+\mathrm{H}]^{+}, \mathrm{R}_{\mathrm{t}}=0.83 \mathrm{~min}$.

5-methyl-4-oxo-N-phenyl-3,4-dihydrothieno[2,3-d]pyrimidine-6-carboxamide (18) was

prepared according to general procedure B using aniline $(50 \mu \mathrm{L}, 0.54 \mathrm{mmol})$. The crude product was purified by reverse phase chromatography (C18 column, 10-40\% $\mathrm{CH}_{3} \mathrm{CN}(\mathrm{B}) / 10 \mathrm{mM}$ aqueous ammonium bicarbonate solution (A)) to give the title product as a pale yellow solid (87 mg, 64 \%). ${ }^{1} \mathrm{H}$ NMR (400 MHz, DMSO-d 6 ) $\delta 12.57$ (br. s, 1H), 10.20 (s, 1H), 8.18 (s, 1H), 7.68 $(\mathrm{d}, J=7.5 \mathrm{~Hz}, 2 \mathrm{H}), 7.36(\mathrm{t}, J=8.0 \mathrm{~Hz}, 2 \mathrm{H}), 7.03-7.18(\mathrm{~m}, 1 \mathrm{H}), 2.73(\mathrm{~s}, 3 \mathrm{H}) ;{ }^{13} \mathrm{C}$ NMR $(101$ MHz, DMSO-d $\left.{ }_{6}\right) \delta 164.2(\mathrm{C}), 160.6(\mathrm{C}=\mathrm{O}), 158.3(\mathrm{C}=\mathrm{O}), 147.4(\mathrm{Ar}-\mathrm{CH}), 138.5(\mathrm{C}), 136.4(\mathrm{C})$ 128.7 (2C, Ar-CH), 127.9 (C), 124.0 (Ar-CH), 123.4 (C), 120.3 (2C, Ar-CH), $15.1\left(\mathrm{CH}_{3}\right)$; LCMS (ESI, high pH) $m / z 286.01[\mathrm{M}+\mathrm{H}]^{+}, \mathrm{R}_{\mathrm{t}}=0.72 \mathrm{~min}$; HRMS (ESI) calcd for $\mathrm{C}_{14} \mathrm{H}_{11} \mathrm{~N}_{3} \mathrm{O}_{2} \mathrm{~S}+\mathrm{H}^{+}$ 286.0650, found 286.0646 (4.08 min); IR (ATR) $\mathrm{cm}^{-1} 3294,3062,3020,2929,2866,1656$, $1634,1595,1580,1529$.

N-cyclopentyl-3,5-dimethyl-4-oxo-3,4-dihydrothieno[2,3-d]pyrimidine-6-carboxamide (19) was prepared according to general procedure A using cyclopentanamine $(0.026 \mathrm{~mL}, 0.268 \mathrm{mmol}$. Purification twice by reverse phase chromatography using the formic acid MDAP (gradient B over $15 \mathrm{~min}$ ) gave the title product as a white solid (20 mg, $28 \%) .{ }^{1} \mathrm{H} \mathrm{NMR}\left(400 \mathrm{MHz}, \mathrm{CDCl}_{3}\right)$ $\delta 8.03(\mathrm{~s}, 1 \mathrm{H}), 5.82(\mathrm{~d}, J=6.5 \mathrm{~Hz}, 1 \mathrm{H}), 4.39$ (apparent sxt, $J=7.0 \mathrm{~Hz}, 1 \mathrm{H}), 3.58(\mathrm{~s}, 3 \mathrm{H}), 2.86$ (s, 3H), $2.05-2.17(\mathrm{~m}, 2 \mathrm{H}), 1.62-1.81(\mathrm{~m}, 4 \mathrm{H}), 1.45-1.57(\mathrm{~m}, 2 \mathrm{H}) ;$ LCMS (ESI, formic) $\mathrm{m} / z$ $292.09[\mathrm{M}+\mathrm{H}]^{+}, \mathrm{R}_{\mathrm{t}}=0.78 \min$. 


\section{3,5-dimethyl-6-(piperidine-1-carbonyl)thieno[2,3-d]pyrimidin-4(3H)-one (20) was prepared}

according to general procedure A using piperidine $(0.04 \mathrm{~mL}, 0.43 \mathrm{mmol})$. Purification by reverse phase chromatography using the formic acid MDAP (gradient B over $15 \mathrm{~min}$ ) gave the title product as a white solid (70 mg, $64 \%$ ). ${ }^{1} \mathrm{H}$ NMR (400 MHz, DMSO-d 6 ) $\delta 8.43(\mathrm{~s}, 1 \mathrm{H}), 3.47$ (br. $\mathrm{s}, 7 \mathrm{H}), 2.43(\mathrm{~s}, 3 \mathrm{H}), 1.56-1.67(\mathrm{~m}, 2 \mathrm{H}), 1.55-1.44(\mathrm{~m}, 4 \mathrm{H})$; LCMS (ESI, formic) $\mathrm{m} / \mathrm{z} 292.17$ $[\mathrm{M}+\mathrm{H}]^{+}, \mathrm{R}_{\mathrm{t}}=0.74 \mathrm{~min}$.

\section{5-methyl-4-oxo-N-(o-tolyl)-3,4-dihydrothieno[2,3-d]pyrimidine-6-carboxamide (21) was} prepared according to general procedure B using $o$-toluidine $(0.4 \mathrm{~mL}, 0.3 \mathrm{mmol})$. Purification by reverse phase chromatography using the formic acid MDAP (gradient B over 15 min) gave the title product as yellow solid (32 mg, $37 \%$ ). ${ }^{1} \mathrm{H}$ NMR (400 MHz, DMSO-d $\left.{ }_{6}\right) \delta 12.55$ (br. s, $\left.1 \mathrm{H}\right)$, 9.69 (s, 1H), 8.17 (s, 1H), 7.39 (br. d, $J=7.5 \mathrm{~Hz}, 1 \mathrm{H}), 7.28$ (br. d, $J=7.0 \mathrm{~Hz}, 1 \mathrm{H}), 7.15-7.25$ $(\mathrm{m}, 2 \mathrm{H}), 2.79(\mathrm{~s}, 3 \mathrm{H}), 2.26(\mathrm{~s}, 3 \mathrm{H})$; LCMS (ESI, formic) $\mathrm{m} / z 300.04[\mathrm{M}+\mathrm{H}]^{+}, \mathrm{R}_{\mathrm{t}}=0.78 \mathrm{~min}$, purity $=94 \%$.

\section{5-methyl-4-oxo-N-(m-tolyl)-3,4-dihydrothieno[2,3-d]pyrimidine-6-carboxamide (22) was} prepared according to general procedure B using $m$-toluidine $(60 \mu \mathrm{L}, 0.57 \mathrm{mmol})$. Purification by reverse phase chromatography using the formic acid MDAP (gradient B over 15 min) gave the title product as a white solid (39 mg, $46 \%) .{ }^{1} \mathrm{H}$ NMR (400 MHz, DMSO-d 6 ) $\delta 12.55$ (br. s, $1 \mathrm{H}), 10.12(\mathrm{~s}, 1 \mathrm{H}), 8.17(\mathrm{~s}, 1 \mathrm{H}), 7.51(\mathrm{~s}, 1 \mathrm{H}), 7.47(\mathrm{~d}, J=8.5 \mathrm{~Hz}, 1 \mathrm{H}), 7.23(\mathrm{t}, J=8.0 \mathrm{~Hz}, 1 \mathrm{H})$, $6.94(\mathrm{~d}, J=7.5 \mathrm{~Hz}, 1 \mathrm{H}), 2.73(\mathrm{~s}, 3 \mathrm{H}), 2.31(\mathrm{~s}, 3 \mathrm{H}) ;{ }^{13} \mathrm{C}$ NMR $\left(101 \mathrm{MHz}, \mathrm{DMSO}-\mathrm{d}_{6}\right) \delta 164.2(\mathrm{C})$, $160.5(\mathrm{C}=\mathrm{O}), 158.3(\mathrm{C}=\mathrm{O}), 147.3(\mathrm{CH}), 138.4(\mathrm{C}), 137.9(\mathrm{C}), 136.3(\mathrm{C}), 128.5(\mathrm{C}), 128.0(\mathrm{CH})$, $124.7(\mathrm{CH}), 123.4(\mathrm{C}), 120.8(\mathrm{CH}), 117.5(\mathrm{CH}), 21.1\left(\mathrm{CH}_{3}\right), 15.0\left(\mathrm{CH}_{3}\right)$; LCMS (ESI, formic) $m / z 300.11[\mathrm{M}+\mathrm{H}]^{+}, \mathrm{R}_{\mathrm{t}}=0.85 \mathrm{~min} ; \mathrm{HRMS}(\mathrm{ESI})$ calcd for $\mathrm{C}_{15} \mathrm{H}_{13} \mathrm{~N}_{3} \mathrm{O}_{2} \mathrm{~S}+\mathrm{H}^{+}$300.0801, found 300.0798 (4.21 $\mathrm{min})$. 


\section{5-methyl-4-oxo-N-(p-tolyl)-3,4-dihydrothieno[2,3-d]pyrimidine-6-carboxamide (23) was}

prepared according to general procedure B using $p$-toluidine ( $80 \mathrm{mg}, 0.75 \mathrm{mmol}$ ). Purification by reverse phase chromatography using the formic acid MDAP (gradient B over 15 min) gave the title product as a white solid (39 mg, $45 \%) .{ }^{1} \mathrm{H}$ NMR (400 MHz, DMSO-d $\left.\mathrm{d}_{6}\right) \delta 12.54$ (br. s, 1H), $10.10(\mathrm{~s}, 1 \mathrm{H}), 8.17(\mathrm{~s}, 1 \mathrm{H}), 7.56(\mathrm{~d}, J=8.5 \mathrm{~Hz}, 2 \mathrm{H}), 7.16(\mathrm{~d}, J=8.5 \mathrm{~Hz}, 2 \mathrm{H}), 2.72(\mathrm{~s}, 3 \mathrm{H})$, $2.28(\mathrm{~s}, 3 \mathrm{H}) ;{ }^{13} \mathrm{C}$ NMR $\left(101 \mathrm{MHz}, \mathrm{DMSO}_{\mathrm{d}}\right) \delta 164.1(\mathrm{C}), 160.4(\mathrm{C}=\mathrm{O}), 158.3(\mathrm{C}=\mathrm{O}), 147.3$ (Ar-CH), 136.2 (C), 136.0 (C), 133.1 (C), 129.0 (2C, Ar-CH), 128.0 (C), 123.4 (C), 120.3 (2C, Ar-CH), $20.5\left(\mathrm{CH}_{3}\right), 15.0\left(\mathrm{CH}_{3}\right)$; LCMS (ESI, formic) $\mathrm{m} / z 300.11[\mathrm{M}+\mathrm{H}]^{+}, \mathrm{R}_{\mathrm{t}}=0.85 \mathrm{~min}$; HRMS (ESI) calcd for $\mathrm{C}_{15} \mathrm{H}_{13} \mathrm{~N}_{3} \mathrm{O}_{2} \mathrm{~S}+\mathrm{H}^{+} 300.0801$, found 300.0803 (4.19 min).

5-methyl-4-oxo-N-(pyridin-3-yl)-3,4-dihydrothieno[2,3-d]pyrimidine-6-carboxamide (24) was prepared according to general procedure B using pyridin-3-amine (57 $\mathrm{mg}, 0.61 \mathrm{mmol})$.

Purification by reverse phase chromatography (5-20\% acetonitrile (B) / $10 \mathrm{mM}$ aqueous ammonium bicarbonate solution (A)). The product was dissolved in $\mathrm{MeOH}$ and transferred in a vial for test to give the title product as $\mathrm{MeOH}$ solvate, yellow solid (70 mg, $46 \%$ \%). ${ }^{1} \mathrm{H}$ NMR (400 MHz, DMSO-d 6 ) $\delta 12.59$ (br. s, $1 \mathrm{H}), 10.39$ (s, 1H), 8.84 (d, $J=2.5 \mathrm{~Hz}, 1 \mathrm{H}), 8.33$ (dd, $J=5.0$, $1.5 \mathrm{~Hz}, 1 \mathrm{H}), 8.19(\mathrm{~s}, 1 \mathrm{H}), 8.07-8.14(\mathrm{~m}, 1 \mathrm{H}), 7.40(\mathrm{dd}, J=8.5,5.0 \mathrm{~Hz}, 1 \mathrm{H}), 4.06(\mathrm{~d}, J=5.0 \mathrm{~Hz}$, $\left.1 \mathrm{H}, \mathrm{CH}_{3} \underline{\mathrm{OH}}\right), 3.17\left(\mathrm{~d}, J=5.0 \mathrm{~Hz}, 3 \mathrm{H}, \underline{\mathrm{CH}_{3}} \underline{\mathrm{OH}}\right), 2.76$ (s, 3H); LCMS (ESI, high pH) $\mathrm{m} / z 286.99$ $[\mathrm{M}+\mathrm{H}]^{+}, \mathrm{R}_{\mathrm{t}}=0.52 \mathrm{~min}$.

N-(isoxazol-3-yl)-5-methyl-4-oxo-3,4-dihydrothieno[2,3-d]pyrimidine-6-carboxamide (25)

A solution of 5-methyl-4-oxo-3,4-dihydrothieno[2,3- $d]$ pyrimidine-6-carboxylic acid 16 (100 $\mathrm{mg}, 0.48 \mathrm{mmol})$ in thionyl chloride $(2 \mathrm{~mL}, 27 \mathrm{mmol})$ was heated at $80{ }^{\circ} \mathrm{C}$ for 3 days before the reaction mixture was concentrated to dryness under reduced pressure. A solution of isoxazol-3- 
amine (160 mg, $1.9 \mathrm{mmol})$ and DIPEA $(0.2 \mathrm{~mL}, 1.2 \mathrm{mmol})$ in DMF $(1.5 \mathrm{~mL})$ dried over molecular sieves $(4 \AA)$ was added to the crude and the reaction mixture was stirred at room temperature with molecular sieves for $24 \mathrm{~h}$. The crude reaction mixture was purified by reverse phase chromatography using formic acid MDAP (gradient A over $15 \mathrm{~min}$ ) to give the title product as white solid (18 mg, $14 \%$ ). ${ }^{1} \mathrm{H}$ NMR (400 MHz, DMSO-d ${ }_{6}$ ) $\delta 11.98$ (br. s, $2 \mathrm{H}$ ), 8.85 $(\mathrm{d}, J=1.5 \mathrm{~Hz}, 1 \mathrm{H}), 8.19(\mathrm{~s}, 1 \mathrm{H}), 6.97(\mathrm{~d}, J=2.0 \mathrm{~Hz}, 1 \mathrm{H}), 2.75(\mathrm{~s}, 3 \mathrm{H})$; LCMS (ESI, formic) $m / z$ $277.06[\mathrm{M}+\mathrm{H}]^{+}, \mathrm{R}_{\mathrm{t}}=0.57 \mathrm{~min}$.

\section{5-methyl-4-oxo-N-(thiophen-2-yl)-3,4-dihydrothieno[2,3-d]pyrimidine-6-carboxamide (26)} was prepared according to general procedure B using thiophen-2-amine (64 $\mathrm{mg}, 0.65 \mathrm{mmol})$ at $40^{\circ} \mathrm{C}$. Purification by reverse phase chromatography using the formic acid MDAP (gradient B over $15 \mathrm{~min})$ to give the title product as a brown solid (21 mg, $15 \%) .{ }^{1} \mathrm{H}$ NMR $(400 \mathrm{MHz}$, DMSO-d $)_{6} \delta 12.59$ (br. s, 1H), $11.42(\mathrm{~s}, 1 \mathrm{H}), 8.19(\mathrm{~d}, J=4.0 \mathrm{~Hz}, 1 \mathrm{H}), 7.05(\mathrm{t}, J=4.0 \mathrm{~Hz}, 1 \mathrm{H})$ 6.90 - $6.93(\mathrm{~m}, 2 \mathrm{H}), 2.76(\mathrm{~s}, 3 \mathrm{H}) ;{ }^{13} \mathrm{C}$ NMR (101 MHz, DMSO-d 6 ) $\delta 164.4(\mathrm{C}), 158.5(\mathrm{C}=\mathrm{O})$, $158.2(\mathrm{C}=\mathrm{O}), 147.6(\mathrm{Ar}-\mathrm{CH}), 139.2(\mathrm{C}), 138.0(\mathrm{C}), 125.4(\mathrm{C}), 124.1(\mathrm{C}), 123.5(\mathrm{Ar}-\mathrm{CH}), 117.9$ (Ar-CH), $112.8(\mathrm{Ar}-\mathrm{CH}), 15.1\left(\mathrm{CH}_{3}\right)$; LCMS (ESI, formic) $m / z 292.03[\mathrm{M}+\mathrm{H}]^{+}, \mathrm{R}_{\mathrm{t}}=0.74$ min; HRMS (ESI) calcd for $\mathrm{C}_{12} \mathrm{H}_{9} \mathrm{~N}_{3} \mathrm{O}_{2} \mathrm{~S}_{2}+\mathrm{H}^{+} 292.0214$, found 292.0214 (4.01 min).

\section{5-methyl-4-oxo-N-(1,3,4-thiadiazol-2-yl)-3,4-dihydrothieno[2,3-d]pyrimidine-6-carboxamide} (27) was prepared according to general procedure B using 2-amino-1,3,4-thiadiazole (62 mg, $0.613 \mathrm{mmol})$ at $40^{\circ} \mathrm{C}$. DMSO $(2 \mathrm{~mL})$ was added to the reaction mixture and the whole solubilised with heating. After cooling a solid precipitated out which was collected by filtration and dried in a vacuum oven overnight to give the title product as yellow solid $(70 \mathrm{mg}, 50 \%) .{ }^{1} \mathrm{H}$ NMR (400 MHz, DMSO-d $\left.)_{6}\right) 14.10$ (br. s, 1H), 12.54 (br. s, 1H), 9.04 (br. s, 1H), 8.18 (d, $J=$ $3.5 \mathrm{~Hz}, 1 \mathrm{H}), 2.89(\mathrm{~s}, 3 \mathrm{H}) ;{ }^{13} \mathrm{C}$ NMR (126 MHz, DMSO-d 6$) \delta 167.6(\mathrm{C}), 166.7(\mathrm{C}=\mathrm{O}), 158.5$ 
$(\mathrm{C}=\mathrm{O}), 146.2(\mathrm{Ar}-\mathrm{CH}), 144.9(\mathrm{Ar}-\mathrm{CH}), 135.6(\mathrm{C}), 134.2(\mathrm{C}), 124.2(\mathrm{C}), 109.5(\mathrm{C}), 14.8\left(\mathrm{CH}_{3}\right)$;

LCMS (ESI, formic) $m / z 294.03[\mathrm{M}+\mathrm{H}]^{+}, \mathrm{Rt}=0.38 \mathrm{~min}$; HRMS (ESI) calcd for

$\mathrm{C}_{10} \mathrm{H}_{7} \mathrm{~N}_{5} \mathrm{O}_{2} \mathrm{~S}_{2}+\mathrm{H}^{+}$294.0119, found 294.0115 (3.22 min); IR (ATR) $\mathrm{cm}^{-1}$ 3142, 3095, 3007, 2930, 1676, 1651, 1552.

Ethyl 2-(2-(5-methyl-4-oxo-3,4-dihydrothieno[2,3-d]pyrimidine-6-

carboxamido)phenyl)acetate (28) was prepared according to general procedure B using ethyl 2(2-aminophenyl)acetate 48 (66 $\mathrm{mg}, 0.4 \mathrm{mmol})$. The crude product was purified by reverse phase chromatography using formic acid MDAP (gradient B over $15 \mathrm{~min}$ ) to give the title product as a yellow solid (46 mg, 40 \%). ${ }^{1} \mathrm{H}$ NMR (400 MHz, DMSO-d 6 ) $\delta 12.56$ (br. s, 1H), 9.75 (s, 1H), $8.17(\mathrm{~d}, J=4.0 \mathrm{~Hz}, 1 \mathrm{H}), 7.42$ (br. d, $J=8.0 \mathrm{~Hz}, 1 \mathrm{H}), 7.29-7.36(\mathrm{~m}, 2 \mathrm{H}), 7.19-7.28(\mathrm{~m}, 1 \mathrm{H})$, $4.04(\mathrm{q}, J=7.0 \mathrm{~Hz}, 2 \mathrm{H}), 3.73(\mathrm{~s}, 2 \mathrm{H}), 2.76(\mathrm{~s}, 3 \mathrm{H}), 1.13(\mathrm{t}, J=7.0 \mathrm{~Hz}, 3 \mathrm{H})$; LCMS (ESI, formic) $m / z 372.07[\mathrm{M}+\mathrm{H}]^{+}, \mathrm{R}_{\mathrm{t}}=0.83 \mathrm{~min}$.

2-(2-(5-methyl-4-oxo-3,4-dihydrothieno[2,3-d]pyrimidine-6-carboxamido)phenyl)acetic acid (29) A solution of ethyl 2-(2-(5-methyl-4-oxo-3,4-dihydrothieno[2,3-d]pyrimidine-6carboxamido)phenyl)acetate $28(30 \mathrm{mg}, 0.1 \mathrm{mmol})$ and lithium hydroxide $(5.8 \mathrm{mg}, 0.2 \mathrm{mmol})$ in a mixture of THF $(0.4 \mathrm{~mL}), \mathrm{MeOH}(0.2 \mathrm{~mL})$ and water $(0.1 \mathrm{~mL})$ was stirred at room temperature for $2 \mathrm{~h}$. Solvents were removed under a stream of nitrogen. The resulting crude product was dissolved in water $(0.5 \mathrm{~mL})$ and $2 \mathrm{M}$ aqueous $\mathrm{HCl}$ solution was added. The resulting precipitate was collected by filtration and dried in a vacuum oven overnight to give the title product as a brown solid (16 mg, 58 \%). ${ }^{1} \mathrm{H}$ NMR (400 MHz, DMSO-d 6 ) $\delta 12.55$ (br. s, 1H), 12.41 (br. s, 1H), $9.74(\mathrm{~s}, 1 \mathrm{H}), 8.17$ (d, $J=3.5 \mathrm{~Hz}, 1 \mathrm{H}), 7.46$ (br. d, $J=7.5 \mathrm{~Hz}, 1 \mathrm{H}), 7.28-7.36$ (m, 2H), 7.18 - $7.25(\mathrm{~m}, 1 \mathrm{H}), 3.66(\mathrm{~s}, 2 \mathrm{H}), 2.77(\mathrm{~s}, 3 \mathrm{H})$; LCMS (ESI, formic) $m / z 344.09[\mathrm{M}+\mathrm{H}]^{+}, \mathrm{R}_{\mathrm{t}}=0.64$ $\min$. 


\section{N-(2-(hydroxymethyl)phenyl)-5-methyl-4-oxo-3,4-dihydrothieno[2,3-d]pyrimidine-6-}

carboxamide (30) TBAF (1 M in THF, $0.39 \mathrm{~mL}, 0.39 \mathrm{mmol})$ was added to a solution of $\mathrm{N}-(2-$ (((tert-butyldimethylsilyl)oxy)methyl)phenyl)-5-methyl-4-oxo-3,4-dihydrothieno[2,3d]pyrimidine-6-carboxamide $\mathbf{5 0}(83 \mathrm{mg}, 0.2 \mathrm{mmol})$ in THF $(1 \mathrm{~mL})$. The reaction mixture was stirred at room temperature for $3 \mathrm{~h}$. Saturated aqueous $\mathrm{NaHCO}_{3}$ solution $(10 \mathrm{~mL})$ and EtOAc $(10$ $\mathrm{mL})$ were added. The organic layer was separated and the aqueous was extracted with EtOAc (2 $\mathrm{x} 10 \mathrm{~mL}$ ). The combined organic layers were passed through a hydrophobic frit and concentrated under reduced pressure. The crude product was purified by reverse phase chromatography using the formic acid MDAP (gradient $\mathrm{C}$ over $15 \mathrm{~min}$ ) to give the title product as a white solid (36 $\mathrm{mg}$, 59 \%). ${ }^{1} \mathrm{H}$ NMR (400 MHz, DMSO-d 6 ) $\delta 12.57$ (br. s, 1H), 9.87 (br. s, 1H), 8.18 (s, 1H), 7.79 (br. d, $J=8.0 \mathrm{~Hz}, 1 \mathrm{H}$ ), 7.40 (br. d, $J=7.5 \mathrm{~Hz}, 1 \mathrm{H}$ ), 7.30 (br. t, $J=8.0 \mathrm{~Hz}, 1 \mathrm{H}$ ), 7.19 (br. t, $J=$ $7.5 \mathrm{~Hz}, 1 \mathrm{H}), 5.63$ (br. s, 1H), $4.61(\mathrm{~s}, 2 \mathrm{H}), 2.83$ (s, 3H); LCMS (ESI, formic) $\mathrm{m} / z 316.00$ $[\mathrm{M}+\mathrm{H}]^{+}, \mathrm{R}_{\mathrm{t}}=0.67 \mathrm{~min}$; HRMS (ESI) calcd for $\mathrm{C}_{15} \mathrm{H}_{13} \mathrm{~N}_{3} \mathrm{O}_{3} \mathrm{~S}+\mathrm{H}^{+}$316.0741, found 316.0756 (3.68min).

\section{5-methyl-4-oxo-N-(2-sulfamoylphenyl)-3,4-dihydrothieno[2,3-d]pyrimidine-6-carboxamide} (31). A solution of 5-methyl-4-oxo-3,4-dihydrothieno[2,3-d]pyrimidine-6-carboxylic acid 16 (60 $\mathrm{mg}, 0.29 \mathrm{mmol})$ in thionyl chloride $(2 \mathrm{~mL}, 27 \mathrm{mmol})$ was refluxed for $16 \mathrm{~h}$ before the reaction mixture was concentrated under reduced pressure. A solution of 2-aminobenzenesulfonamide (59.0 $\mathrm{mg}, 0.34 \mathrm{mmol})$ and DIPEA $(0.1 \mathrm{~mL}, 0.6 \mathrm{mmol})$ in DMF $(1.5 \mathrm{~mL})$ was dried over molecular sieves ( $4 \AA$ ) and then added to the acid chloride intermediate under nitrogen. The reaction mixture was stirred at room temperature under nitrogen for $5 \mathrm{~h}$. The crude product was purified by reverse phase chromatography using the formic acid MDAP (gradient A over 15 min) to give the title product as an orange solid (11 mg, $11 \%) .{ }^{1} \mathrm{H}$ NMR $\left(400 \mathrm{MHz}, \mathrm{DMSO}-\mathrm{d}_{6}\right) \delta$ 
12.56 (br. s, $1 \mathrm{H}), 8.17(\mathrm{~d}, J=3.5 \mathrm{~Hz}, 1 \mathrm{H}), 7.67(\mathrm{dd}, J=8.0,1.5 \mathrm{~Hz}, 1 \mathrm{H}), 7.29-7.36(\mathrm{~m}, 1 \mathrm{H})$, $6.84(\mathrm{~d}, J=8.5 \mathrm{~Hz}, 1 \mathrm{H}), 6.68-6.74(\mathrm{~m}, 1 \mathrm{H}), 2.69(\mathrm{~s}, 3 \mathrm{H})$, amide $\mathrm{NH}$ and $\mathrm{NH}_{2}$ protons not visible; LCMS (ESI, formic) $m / z 364.97[\mathrm{M}+\mathrm{H}]^{+}, \mathrm{R}_{\mathrm{t}}=0.62 \mathrm{~min}$.

\section{5-methyl-N-(2-(methylsulfonyl)phenyl)-4-oxo-3,4-dihydrothieno[2,3-d]pyrimidine-6-}

carboxamide (32). 5-methyl-4-oxo-3,4-dihydrothieno[2,3-d]pyrimidine-6-carboxylic acid 16 (100 mg, $0.48 \mathrm{mmol})$ in thionyl chloride $(2 \mathrm{~mL}, 27 \mathrm{mmol})$ was heated at $50^{\circ} \mathrm{C}$ for 2 days before the reaction mixture was concentrated under reduced pressure. A solution of DMF $(1.5 \mathrm{~mL})$ and DIPEA (0.2 mL, $1.1 \mathrm{mmol})$ dried over molecular sieves (4 $\AA$ ) was added to the crude intermediate followed by 2-(methylsulfonyl)aniline $(250 \mathrm{mg}, 1.5 \mathrm{mmol})$. The reaction mixture was stirred at room temperature with molecular sieves under nitrogen for $16 \mathrm{~h}$ before being heated to $50{ }^{\circ} \mathrm{C}$ for a further $16 \mathrm{~h}$. The crude mixture was purified by reverse phase chromatography using the formic acid MDAP (gradient B over $15 \mathrm{~min}$ ) to give the title product as a yellow solid (16 mg, 9\%). ${ }^{1} \mathrm{H}$ NMR (400 MHz, DMSO-d 6 ) $\delta 8.19-8.24(\mathrm{~m}, 2 \mathrm{H}), 7.96(\mathrm{dd}$, $J=8.0,1.5 \mathrm{~Hz}, 1 \mathrm{H}), 7.75-7.81(\mathrm{~m}, 1 \mathrm{H}), 7.47(\mathrm{td}, J=8.5,1.0 \mathrm{~Hz}, 1 \mathrm{H}), 3.33(\mathrm{~s}, 3 \mathrm{H}), 2.85(\mathrm{~s}$, $3 \mathrm{H}$ ), amide $\mathrm{NH}$ protons not visible; LCMS (ESI, formic) $m / z 364.11[\mathrm{M}+\mathrm{H}]^{+}, \mathrm{R}_{\mathrm{t}}=0.76 \mathrm{~min}$.

\section{N-(4-carbamoylphenyl)-3,4-dichlorobenzamide (36). HATU (191 mg, 0.5 mmol), 4-}

aminobenzamide $(68 \mathrm{mg}, 0.5 \mathrm{mmol})$ and DIPEA $(0.15 \mathrm{~mL}, 0.84 \mathrm{mmol})$ were added to a solution of 3,4-dichlorobenzoic acid ( $80 \mathrm{mg}, 0.42 \mathrm{mmol})$ in DMF $(1.5 \mathrm{~mL})$ and the reaction mixture was stirred at room temperature for $3 \mathrm{~h}$. Saturated aqueous sodium bicarbonate solution $(25 \mathrm{~mL})$ was added and the aqueous phase was extracted with DCM $(2 \times 25 \mathrm{~mL})$. Solid was present in both phases. The solid was collected by filtration under vacuum and dried in a vacuum oven to give the title product as a white solid (87 mg, $65 \%) .{ }^{1} \mathrm{H}$ NMR (400 MHz, DMSO-d 6 ) $\delta 10.55$ (br. s, 
1H), $8.23(\mathrm{~d}, J=2.0 \mathrm{~Hz}, 1 \mathrm{H}), 7.95(\mathrm{dd}, J=8.5,2.0 \mathrm{~Hz}, 1 \mathrm{H}), 7.77-7.91(\mathrm{~m}, 6 \mathrm{H}), 7.24$ (br. s, 1H); LCMS (ESI, formic) $m / z 309.03[\mathrm{M}+\mathrm{H}]^{+}, \mathrm{R}_{\mathrm{t}}=0.92 \mathrm{~min}$.

\section{General Procedure C for Suzuki Coupling}

A mixture of the appropriate aryl halide (1 eq.), (1 $H$-pyrazol-3-yl)boronic acid. $3 \mathrm{H}_{2} \mathrm{O}(2$ eq. $)$, $\mathrm{Pd}\left(\mathrm{PPh}_{3}\right)_{4}(15 \mathrm{~mol} \%)$, NMP and saturated aqueous sodium carbonate solution (1 eq.) was heated at $130{ }^{\circ} \mathrm{C}$ for $20 \mathrm{~min}$ in a microwave reactor. The reaction mixture was filtered and solvent was evaporated. The crude product was purified by reverse phase chromatography to give the desired final product

$\mathrm{N}-(4-(1 \mathrm{H}-$ pyrazol-3-yl)phenyl)benzamide (37) was prepared according to general procedure C using $N$-(4-bromophenyl)benzamide $43(55 \mathrm{mg}, 0.2 \mathrm{mmol})$. The crude product was purified by reverse phase chromatography using the formic acid MDAP (gradient B over 15 min) to give the title product as a white solid (35 mg, $67 \%$ ). ${ }^{1} \mathrm{H}$ NMR (400 MHz, DMSO-d $\left.{ }_{6}\right) \delta 13.20-12.80(2 \mathrm{br}$. s, 1H, two pyrazole isomers visible), 10.27 (br. s, 1H), $7.93-8.01(\mathrm{~m}, 2 \mathrm{H}), 7.70-7.88(\mathrm{~m}, 5 \mathrm{H})$, 7.48 - 7.64 (m, 3H), 6.68 (br. s, 1H); LCMS (ESI, formic) $m / z 264.11[\mathrm{M}+\mathrm{H}]^{+}, \mathrm{R}_{\mathrm{t}}=0.82 \mathrm{~min}$; HRMS (ESI) calcd for $\mathrm{C}_{16} \mathrm{H}_{13} \mathrm{~N}_{3} \mathrm{O}+\mathrm{H}^{+}$264.1131, found 264.1125 (3.99 min).

\section{2-(2-((4-(1H-pyrazol-3-yl)phenyl)carbamoyl)phenyl)acetic acid (38) was prepared according} to general procedure $\mathrm{C}$ using methyl 2-(2-((4-bromophenyl)carbamoyl)phenyl)acetate 44 (60 mg, $0.172 \mathrm{mmol}$. The crude product was purified by reverse phase chromatography using the formic acid MDAP (gradient B over $15 \mathrm{~min}$ ) to give the title product as a white solid $(33 \mathrm{mg}, 60 \%) .{ }^{1} \mathrm{H}$ NMR (600 MHz, DMSO-d 6 ) $\delta 12.59$ (br. s, 1H), 10.47 (br. s, 1H), 7.73 - 7.79 (m, 5H), 7.68 (br. $\mathrm{s}, 1 \mathrm{H}), 7.60(\mathrm{~d}, J=7.5 \mathrm{~Hz}, 1 \mathrm{H}), 7.44-7.48(\mathrm{~m}, 1 \mathrm{H}), 7.34-7.42(\mathrm{~m}, 2 \mathrm{H}), 6.65(\mathrm{~d}, J=2.0 \mathrm{~Hz}$, 
1H), 3.84 (s, 2H); LCMS (ESI, formic) $\mathrm{m} / z$ 322.07 [M+H $]^{+}, \mathrm{R}_{\mathrm{t}}=0.72 \mathrm{~min}$; HRMS (ESI) calcd for $\mathrm{C}_{18} \mathrm{H}_{15} \mathrm{~N}_{3} \mathrm{O}_{3}+\mathrm{H}^{+}$322.1186, found 322.1187 (3.64min).

N-(4-carbamoylphenyl)benzamide (39). HATU (300 mg, $0.8 \mathrm{mmol})$, 4-aminobenzamide (107 $\mathrm{mg}, 0.8 \mathrm{mmol})$ and DIPEA $(0.23 \mathrm{~mL}, 1.3 \mathrm{mmol})$ were added to a solution of benzoic acid (80 $\mathrm{mg}, 0.66 \mathrm{mmol})$ in DMF $(1.5 \mathrm{~mL})$ and the reaction mixture was stirred at room temperature overnight. Saturated aqueous sodium bicarbonate solution $(25 \mathrm{~mL})$ was added and the aqueous phase was extracted with DCM $(2 \times 25 \mathrm{~mL})$. Some solid remained in the aqueous phase and was collected by filtration. LCMS of the solid and the organic phase showed desired product present in both. The organic phase was passed through a hydrophobic frit and concentrated under reduced pressure. The resulting crude product was combined with the solid isolated by filtration prior purification. The resulting crude was purified by reverse phase chromatography using the formic acid MDAP (gradient B over $15 \mathrm{~min}$ ) to give the title product as a white solid (67 $\mathrm{mg}, 41$ \%). ${ }^{1} \mathrm{H}$ NMR (400 MHz, DMSO-d 6 ) $\delta 10.41(\mathrm{~s}, 1 \mathrm{H}), 7.92$ - $8.02(\mathrm{~m}, 2 \mathrm{H}), 7.78$ - $7.92(\mathrm{~m}, 5 \mathrm{H})$, $7.57-7.66(\mathrm{~m}, 1 \mathrm{H}), 7.49-7.58(\mathrm{~m}, 2 \mathrm{H}), 7.22$ (br. s, 1H); ${ }^{13} \mathrm{C}$ NMR $\left(101 \mathrm{MHz}, \mathrm{DMSO}-\mathrm{d}_{6}\right) \delta$ $167.3(\mathrm{C}=\mathrm{O}), 165.8(\mathrm{C}=\mathrm{O}), 141.8(\mathrm{C}), 134.7(\mathrm{C}), 131.7$ (2C, Ar-CH), $129.1(2 \mathrm{C}, \mathrm{Ar}-\mathrm{CH}), 128.4$ (2C, Ar-CH), 128.2 (2C, Ar-CH), 127.7 (C), 119.3 (Ar-CH); LCMS (ESI, formic) $m / z 241.11$ $[\mathrm{M}+\mathrm{H}]^{+}, \mathrm{R}_{\mathrm{t}}=0.66 \mathrm{~min}$; HRMS (ESI) calcd for $\mathrm{C}_{14} \mathrm{H}_{12} \mathrm{~N}_{2} \mathrm{O}_{2}+\mathrm{H}^{+}$241.0972, found 241.0967 (3.29 $\min )$; IR (ATR) $\mathrm{cm}^{-1} 3383,3308,3163,1650,1606,1516$.

4-(1-oxo-3,4-dihydroisoquinolin-2(1H)-yl)benzamide (40). A mixture of 4-(1-oxo-3,4dihydroisoquinolin-2(1H)-yl)benzonitrile 46 (40 mg, $0.16 \mathrm{mmol}), 2 \mathrm{M}$ aqueous $\mathrm{NaOH}$ solution $(1.2 \mathrm{~mL}, 2.4 \mathrm{mmol})$ and $30 \%$ aqueous $\mathrm{H}_{2} \mathrm{O}_{2}$ solution $(54 \mu \mathrm{L}, 0.53 \mathrm{mmol})$ in EtOH $(1 \mathrm{~mL})$ was heated at $50^{\circ} \mathrm{C}$ for $20 \mathrm{~h}$. The reaction mixture was poured in saturated aqueous sodium sulfite solution and acidified to $\mathrm{pH} 1$ with aqueous $\mathrm{H}_{2} \mathrm{SO}_{4}$ solution. The mixture was concentrated under 
reduced pressure. Water and DCM were added. The aqueous phase was extracted with DCM. The combined organic phases were passed through a hydrophobic frit and concentrated under reduced pressure. The resulting crude product was purified by reverse phase chromatography using the formic acid MDAP (gradient B over $15 \mathrm{~min}$ ) to give the title product as a white solid ( 8 mg, $19 \%) ;{ }^{1} \mathrm{H}$ NMR (400 MHz, DMSO-d 6 ) $\delta 7.86$ - $8.00(\mathrm{~m}, 4 \mathrm{H}), 7.45$ - $7.58(\mathrm{~m}, 3 \mathrm{H}), 7.35$ $7.44(\mathrm{~m}, 2 \mathrm{H}), 7.27-7.34(\mathrm{~m}, 1 \mathrm{H}), 4.00(\mathrm{t}, J=6.5 \mathrm{~Hz}, 2 \mathrm{H}), 3.14(\mathrm{t}, J=6.5 \mathrm{~Hz}, 2 \mathrm{H})$; LCMS (ESI, formic) $m / z 267.07[\mathrm{M}+\mathrm{H}]^{+}, \mathrm{R}_{\mathrm{t}}=0.71 \mathrm{~min}$; HRMS (ESI) calcd for $\mathrm{C}_{16} \mathrm{H}_{15} \mathrm{~N}_{2} \mathrm{O}_{2}+\mathrm{H}^{+}$267.1128, found 267.1125 (3.56 $\mathrm{min})$.

N-(2-(1H-pyrazol-3-yl)pyrimidin-5-yl)benzamide (41) was prepared according to general procedure C using $N$-(2-chloropyrimidin-5-yl)benzamide 45 (60 mg, $0.26 \mathrm{mmol})$. The resulting crude product was purified by reverse phase chromatography using the high pH MDAP (gradient B over $15 \mathrm{~min})$ to give the title product as a white solid (28 mg, $41 \%) .{ }^{1} \mathrm{H} \mathrm{NMR}(400 \mathrm{MHz}$, DMSO-d $)_{6} \delta 13.02$ - 13.79 (br. d, 1H, two pyrazole isomers visible), 10.68 (br. s, 1H), 9.23 (s, 2H), $8.00-8.05(\mathrm{~m}, 2 \mathrm{H}), 7.62-7.68(\mathrm{~m}, 2 \mathrm{H}), 7.55-7.61(\mathrm{~m}, 2 \mathrm{H}), 6.90(\mathrm{~d}, J=1.5 \mathrm{~Hz}, 1 \mathrm{H}) ;{ }^{13} \mathrm{C}$ NMR (101 MHz, DMSO-d 6 ) $\delta 177.6(\mathrm{Ar}-\mathrm{CH}), 165.9(\mathrm{C}=\mathrm{O}), 148.5$ (2C, Ar-CH), 133.7 (C), 132.6 (C), 132.2 (Ar-CH), 128.5 (2C, Ar-CH), 127.7 (2C, Ar-CH), 119.1 (C), 105.4 (Ar-CH), one carbon too weak to assign should be around $150 \mathrm{ppm}$; LCMS (ESI, high pH) $m / z 266.04$ $[\mathrm{M}+\mathrm{H}]^{+}, \mathrm{R}_{\mathrm{t}}=0.74$ min; HRMS (ESI) calcd for $\mathrm{C}_{14} \mathrm{H}_{11} \mathrm{~N}_{5} \mathrm{O}+\mathrm{H}^{+} 266.1029$, found 266.1036 (3.47min).

2-(4-(1H-pyrazol-3-yl)phenyl)-3,4-dihydroisoquinolin-1(2H)-one (42) was prepared according to general procedure C using 2-(4-bromophenyl)-3,4-dihydroisoquinolin-1(2H)-one 47 (100 mg, $0.331 \mathrm{mmol})$. The resulting crude product was purified by reverse phase chromatography using the formic acid MDAP (15-55\%(B) over 15 mins) to give the title product as a white solid (45 
mg, $47 \%$ ). ${ }^{1} \mathrm{H}$ NMR (400 MHz, DMSO-d 6 ) $\delta 13.31+12.89$ (2 br. s, $\left.1 \mathrm{H}\right), 7.95$ (dd, $J=7.5,1.0$ Hz, 1H), $7.75-7.88$ (m, 3H), 7.54 (td, $J=7.5,1.5 \mathrm{~Hz}, 1 \mathrm{H}), 7.46$ (br. s, 1H), 7.36-7.43 (m, 3H), 6.73 (br. s, 1H), 3.99 (t, $J=6.5 \mathrm{~Hz}, 2 \mathrm{H}), 3.15$ (t, $J=6.5 \mathrm{~Hz}, 2 \mathrm{H})$; LCMS (ESI, high pH) $\mathrm{m} / z$ $290.23[\mathrm{M}+\mathrm{H}]^{+}, \mathrm{R}_{\mathrm{t}}=0.89 \mathrm{~min}$.

N-(4-bromophenyl)benzamide (43). HATU (335 mg, $0.88 \mathrm{mmol})$ and DIPEA (0.26 mL, 1.5 mmol) were added to a solution of benzoic acid $(90 \mathrm{mg}, 0.74 \mathrm{mmol})$ in DMF (3 mL). The mixture was stirred at room temperature for $5 \mathrm{~min}$. 4-bromoaniline (152 $\mathrm{mg}, 0.88 \mathrm{mmol}$ ) was then added and the reaction mixture was stirred at room temperature for $15 \mathrm{~h}$. The crude reaction mixture was purified by reverse phase chromatography $\left(30-85 \% \mathrm{CH}_{3} \mathrm{CN}+0.01 \%\right.$ formic acid (B) $/ \mathrm{H}_{2} \mathrm{O}+0.01 \%$ formic acid (A), $43 \mathrm{~g} \mathrm{C18}$ column) to give the title product as a white solid (120 mg, $49 \%$ ). ${ }^{1} \mathrm{H}$ NMR (400 MHz, DMSO-d 6 ) $\delta 10.34$ (s, 1H), 7.94 (br. d, $\left.J=7.0 \mathrm{~Hz}, 2 \mathrm{H}\right)$, 7.77 (br. d, $J=9.0 \mathrm{~Hz}, 2 \mathrm{H}), 7.59-7.62(\mathrm{~m}, 1 \mathrm{H}), 7.50$ - $7.56(\mathrm{~m}, 4 \mathrm{H})$; LCMS (ESI, formic) $m / z$ $275.97+277.93[\mathrm{M}+\mathrm{H}]^{+}, \mathrm{R}_{\mathrm{t}}=1.09 \mathrm{~min}$.

Methyl 2-(2-((4-bromophenyl)carbamoyl)phenyl)acetate (44). HATU (335 mg, $0.88 \mathrm{mmol})$ and DIPEA (0.26 mL, $1.49 \mathrm{mmol})$ were added to a solution of 2-(2-methoxy-2-oxoethyl)benzoic acid (135 $\mathrm{mg}, 0.69 \mathrm{mmol})$ in DMF (3 mL). The mixture was stirred at room temperature for 5 min. 4-bromoaniline (152 $\mathrm{mg}, 0.88 \mathrm{mmol}$ ) was then added and the reaction mixture was stirred at room temperature for $15 \mathrm{~h}$. The crude reaction mixture was purified by reverse phase chromatography $\left(30-85 \% \mathrm{CH}_{3} \mathrm{CN}+0.01 \%\right.$ formic acid (B) $/ \mathrm{H}_{2} \mathrm{O}+0.01 \%$ formic acid (A), 43 g C18 column) to give the title product as a beige solid (210 mg, $68 \%$ ). ${ }^{1} \mathrm{H} \mathrm{NMR} \mathrm{(400} \mathrm{MHz,}$ $\left.\mathrm{DMSO}_{-} \mathrm{d}_{6}\right) \delta 10.44$ (s, 1H), 7.69 (br. d., $\left.J=9.0 \mathrm{~Hz}, 2 \mathrm{H}\right), 7.60$ (br. d, $J=7.5 \mathrm{~Hz}, 1 \mathrm{H}$ ), $7.34-7.54$ (m, 5H), $3.90(\mathrm{~s}, 2 \mathrm{H}), 3.53(\mathrm{~s}, 3 \mathrm{H})$; LCMS (ESI, formic) $m / z$ 347.97, $349.93[\mathrm{M}+\mathrm{H}]^{+}, \mathrm{R}_{\mathrm{t}}=1.08$ $\min$. 
N-(2-chloropyrimidin-5-yl)benzamide (45). HATU (747 mg, $1.96 \mathrm{mmol})$ and DIPEA (0.57 $\mathrm{mL}, 3.27 \mathrm{mmol}$ ) were added to a solution of benzoic acid (200 $\mathrm{mg}, 1.64 \mathrm{mmol})$ in DMF. The mixture was stirred at room temperature for $5 \mathrm{~min}$. 2-Chloropyrimidin-5-amine (255 mg, 1.97 mmol) was then added and the reaction mixture was stirred at room temperature for $3 \mathrm{~h}$. The reaction mixture was then heated at $40{ }^{\circ} \mathrm{C}$ for $15 \mathrm{~h}$. Additional 2-chloropyrimidin-5-amine (125 $\mathrm{mg}, 0.97 \mathrm{mmol}$ ) was added and the reaction mixture was heated at $40{ }^{\circ} \mathrm{C}$ for $5 \mathrm{~h}$. Solvent was evaporated under reduced pressure. The resulting crude product was purified by reverse phase chromatography (20-60 \% MeOH (B) / water $+0.1 \%$ formic acid (A), C18 GOLD column) to give the title product as a brown solid $(175 \mathrm{mg}, 46 \%) .{ }^{1} \mathrm{H}$ NMR $\left(400 \mathrm{MHz}, \mathrm{DMSO}-\mathrm{d}_{6}\right) \delta 10.77$ (br. s, 1H), $9.14(\mathrm{~s}, 2 \mathrm{H}), 7.98-8.02(\mathrm{~m}, 2 \mathrm{H}), 7.62-7.69(\mathrm{~m}, 1 \mathrm{H}), 7.58$ (apparent triplet, $J=7.0$, 8.0 Hz, 2H); LCMS (ESI, high pH) $m / z 234.09[\mathrm{M}+\mathrm{H}]^{+}, \mathrm{R}_{\mathrm{t}}=0.84 \mathrm{~min}$.

\section{4-(1-oxo-3,4-dihydroisoquinolin-2(1H)-yl)benzonitrile (46). A mixture of 3,4-} dihydroisoquinolin-1(2H)-one (62 mg, $0.42 \mathrm{mmol})$, 4-iodobenzonitrile (195 mg, $0.85 \mathrm{mmol}$ ), potassium carbonate $(59 \mathrm{mg}, 0.43 \mathrm{mmol})$ and copper(I) iodide (16 mg, $0.084 \mathrm{mmol})$ in DMF (1 $\mathrm{mL}$ ) was heated at $160{ }^{\circ} \mathrm{C}$ overnight under nitrogen. The reaction mixture was cooled and poured into saturated aqueous $\mathrm{NH}_{4} \mathrm{OH}$ solution and EtOAc. The phases were separated and the aqueous phase was extracted with EtOAc. The combined organic phases were washed with brine, separated, passed through a hydrophobic frit and concentrated under reduced pressure. The resulting crude product was then purified by reverse phase chromatography using the formic acid MDAP (gradient $\mathrm{C}$ over $15 \mathrm{~min}$ ) to give the title product as a white solid $\left(69 \mathrm{mg}, 66 \%\right.$ ). ${ }^{1} \mathrm{H}$ NMR (400 MHz, DMSO-d 6 ) $\delta 7.93-7.99(\mathrm{~m}, 1 \mathrm{H}), 7.88(\mathrm{~d}, J=9.0 \mathrm{~Hz}, 2 \mathrm{H}), 7.66(\mathrm{~d}, J=9.0 \mathrm{~Hz}$, 2H), $7.56(\mathrm{td}, J=7.5,1.5 \mathrm{~Hz}, 1 \mathrm{H}), 7.36-7.44(\mathrm{~m}, 2 \mathrm{H}), 4.03(\mathrm{t}, J=6.5 \mathrm{~Hz}, 2 \mathrm{H}), 3.15(\mathrm{t}, J=6.5$ $\mathrm{Hz}, 2 \mathrm{H}$ ); LCMS (ESI, formic) $m / z 249.12[\mathrm{M}+\mathrm{H}]^{+}, \mathrm{R}_{\mathbf{t}}=0.94 \mathrm{~min}$. 


\section{2-(4-bromophenyl)-3,4-dihydroisoquinolin-1(2H)-one (47). A mixture of 3,4-}

dihydroisoquinolin-1(2H)-one (200 mg, $1.36 \mathrm{mmol})$, 1-bromo-4-iodobenzene (769 mg, 2.72 mmol), copper(I) iodide (52 mg, $0.27 \mathrm{mmol})$ and potassium carbonate $(207 \mathrm{mg}, 1.495 \mathrm{mmol})$ in DMF (3 mL) was heated at $160^{\circ} \mathrm{C}$ overnight. The reaction mixture was cooled and poured into saturated aqueous $\mathrm{NH}_{4} \mathrm{OH}$ solution and EtOAc. The two phases were separated and the aqueous phase was extracted with EtOAc. The combined organic phases were washed with brine, separated, passed through a hydrophobic frit and evaporated under reduced pressure. The resulting crude product was purified by reverse phase chromatography (Redisep C18 column GOLD, $50 \mathrm{~g}-40-85 \%$ acetonitrile (B)/ water $+0.1 \%$ formic acid (A) gradient) to give the title product as a white solid (242 mg, $59 \%) .{ }^{1} \mathrm{H}$ NMR (400 MHz, DMSO-d $\left.{ }_{6}\right) \delta 7.94(\mathrm{~d}, J=8.0 \mathrm{~Hz}$, 1H), 7.58-7.63 (m, 2H), $7.54(\mathrm{td}, J=7.5,1.5 \mathrm{~Hz}, 1 \mathrm{H}), 7.34-7.42(\mathrm{~m}, 4 \mathrm{H}), 3.95(\mathrm{t}, J=6.5 \mathrm{~Hz}$, 2H), $3.13(\mathrm{t}, J=6.5 \mathrm{~Hz}, 2 \mathrm{H})$; LCMS (ESI, high pH) $m / z 301.77+303.75[\mathrm{M}+\mathrm{H}]^{+}, \mathrm{R}_{\mathrm{t}}=1.09 \mathrm{~min}$.

Ethyl 2-(2-aminophenyl)acetate (48). A solution of ethyl 2-(2-nitrophenyl)acetate (200 mg, $0.96 \mathrm{mmol})$ in $\mathrm{EtOH}(40 \mathrm{~mL})$ was pumped through an $\mathrm{H}$-cube $(10 \% \mathrm{Pd} / \mathrm{C}$ catcart cartridge, 20 ${ }^{\circ} \mathrm{C}$, full $\mathrm{H}_{2}$ ). Solvent was evaporated under reduced pressure to give the title product as an orange gum (148 mg, $86 \%$ \%). ${ }^{1} \mathrm{H}$ NMR (400 MHz, DMSO-d 6 ) $\delta 6.90-6.99$ (m, 2H), 6.65 (dd, $J=8.0$, $1.0 \mathrm{~Hz}, 1 \mathrm{H}), 6.51$ (apparent dt, $J=7.5,1.5 \mathrm{~Hz}, 1 \mathrm{H}), 4.84$ (br. s, 2H), 4.07 (q, $J=7.0 \mathrm{~Hz}, 2 \mathrm{H})$, $3.49(\mathrm{~s}, 2 \mathrm{H}), 1.18(\mathrm{t}, J=7.0 \mathrm{~Hz}, 3 \mathrm{H})$; LCMS (ESI, formic) $m / z 180.06[\mathrm{M}+\mathrm{H}]^{+}, \mathrm{R}_{\mathrm{t}}=0.70 \mathrm{~min}$.

2-(((tert-butyldimethylsilyl)oxy)methyl)aniline (49). Tert-butyldimethylsilyl chloride (673 mg, $4.47 \mathrm{mmol})$ and imidazole $(553 \mathrm{mg}, 8.12 \mathrm{mmol})$ were added to a solution of (2aminophenyl)methanol (500 $\mathrm{mg}, 4.06 \mathrm{mmol})$ in $\mathrm{CH}_{2} \mathrm{Cl}_{2}(6 \mathrm{~mL})$. The reaction mixture was stirred at room temperature for $14 \mathrm{~h} . \mathrm{CH}_{2} \mathrm{Cl}_{2}(5 \mathrm{~mL})$ and water $(10 \mathrm{~mL})$ were added and the organic layer was separated using a hydrophobic frit before being concentrated under reduced pressure to 
give the title product as an orange liquid (889 mg, $92 \%) .{ }^{1} \mathrm{H}$ NMR (400 MHz, DMSO-d 6 ) $\delta 7.07$ (br. d, $J=7.5 \mathrm{~Hz}, 1 \mathrm{H}), 6.96$ (apparent dt, $J=7.5,1.5 \mathrm{~Hz}, 1 \mathrm{H}), 6.62(\mathrm{dd}, J=8.0,1.0 \mathrm{~Hz}, 1 \mathrm{H})$, 6.54 (apparent dt, $J=7.5,1.0 \mathrm{~Hz}, 1 \mathrm{H}), 4.83$ (br. s., $2 \mathrm{H}), 4.57$ (s, 2H), 0.89 (s, 9H), 0.06 (s, 6H); LCMS (ESI, formic) $m / z 238.14[\mathrm{M}+\mathrm{H}]^{+}, \mathrm{R}_{\mathrm{t}}=1.36 \mathrm{~min}$.

\section{N-(2-(((tert-butyldimethylsilyl)oxy)methyl)phenyl)-5-methyl-4-oxo-3,4-dihydrothieno[2,3-} d]pyrimidine-6-carboxamide (50) was prepared according to general procedure B using 2-((tertbutyldimethylsilyl)oxy)methyl)aniline 49 (140 mg, $0.59 \mathrm{mmol})$. The crude product was purified by reverse phase chromatography (43 g C18 column, 40-80 \% $\mathrm{CH}_{3} \mathrm{CN}+0.1 \%$ formic acid (B) / $\mathrm{H}_{2} \mathrm{O}+0.1 \%$ formic acid (A) over $25 \mathrm{~min}$ ) to give the title product as a yellow solid (90 $\mathrm{mg}, 44$ \%). ${ }^{1} \mathrm{H}$ NMR (400 MHz, DMSO-d 6 ) $\delta 12.57$ (br. s, 1H), 9.63 (s, 1H), $8.18(\mathrm{~s}, 1 \mathrm{H}), 7.60(\mathrm{dd}, J=$ 8.0, 1.0 Hz, 1H), $7.46(\mathrm{dd}, J=7.5,1.0 \mathrm{~Hz}, 1 \mathrm{H}), 7.32$ (apparent td, $J=8.0,1.5 \mathrm{~Hz}, 1 \mathrm{H}), 7.26$ (apparent td, $J=7.5,1.0 \mathrm{~Hz}, 1 \mathrm{H}), 4.77(\mathrm{~s}, 2 \mathrm{H}), 2.80(\mathrm{~s}, 3 \mathrm{H}), 0.87(\mathrm{~s}, 9 \mathrm{H}), 0.06(\mathrm{~s}, 6 \mathrm{H}) . \mathrm{LCMS}$ (ESI, formic) $m / z 430.14[\mathrm{M}+\mathrm{H}]^{+}, \mathrm{R}_{\mathrm{t}}=1.32 \mathrm{~min}$.

\section{Chemi-Luminescent Nitrogen Detection (CLND) solubility determination}

GSK in-house kinetic solubility assay: $5 \mu \mathrm{L}$ of $10 \mathrm{mM}$ DMSO stock solution was diluted to $100 \mu \mathrm{L}$ with $\mathrm{pH} 7.4$ phosphate buffered saline, equilibrated for 1 hour at room temperature and filtered through Millipore Multiscreen $\mathrm{HTS}_{-} \mathrm{PCF}$ filter plates (MSSL BPC). The filtrate was quantified by suitably calibrated flow injection Chemi-Luminescent Nitrogen Detection. The standard error of the CLND solubility determination is $\pm 30 \mu \mathrm{M}$, the upper limit of the solubility was $500 \mu \mathrm{M}$ when working from $10 \mathrm{mM}$ DMSO stock solution.

\section{Calculated Properties}


Calculated partition coefficient (clogP) was computed using the BioByte algorithm, version 5.4 (BioByte Corp., 201 W. 4th St., \#204, Claremont, CA 91711-4707)

\section{BCATm fluorescent assay}

All reagents were purchased from Sigma-Aldrich Ltd. (Gillingham, Dorset, UK) unless otherwise stated. Assay buffer was $50 \mathrm{mM}$ HEPES (pH 7.5), $50 \mathrm{mM} \mathrm{NaCl}$ and $1 \mathrm{mM} \mathrm{CHAPS}$. Horseradish Peroxidase was initially diluted to 500 units/ml in water. 4-methyl-2-oxovalerate was initially diluted to $10 \mathrm{mM}$ in assay buffer. L-Leucine and $\alpha$-ketoglutarate were both initially diluted to $100 \mathrm{mM}$ in $50 \mathrm{mM}$ HEPES (pH 7.5) with pyridoxal phosphate (PLP) initially diluted to $10 \mathrm{mM}$ in $50 \mathrm{mM}$ HEPES (pH 7.5). Amplex red (Invitrogen, Paisley, UK) was initially diluted to $20 \mathrm{mM}$ in DMSO.

BCATm and L-GOX protein were cloned, expressed, and isolated in house (GSK, Stevenage, UK). The assay monitors the production of L-glutamate from branch chain amino-acids and $\alpha$ ketoglutarate through the coupling of hBCATm activity to two additional enzymes, L-Glutamate Oxidase (L-GOx) and Horseradish Peroxidase (HRP). L-GOx catabolises L-glutamate to generate $\alpha$-Ketoglutarate and hydrogen peroxide, the latter being utilised by HRP and leading to the formation of fluorescent resorufin from the redox sensitive dye Amplex Red.

The BCATm fluorescent assay was carried out in low volume 384-well plates (Greiner Bioone, Stonehouse, UK) at a final volume of $10 \mu \mathrm{L}$ per well. Test compounds were added to plates as $50 \mathrm{~nL}$ solutions in DMSO using an Echo 555 acoustic dispenser (Labcyte, Sunnyvale, CA) prior to the addition of assay components. Additionally, $50 \mathrm{~nL}$ DMSO or positive control (5chloro-2benzenzofurancaroxylic acid 2-[[2-(trifluromethyl)phenyl]sulfonyl] hydrazide; emolecules) was included in two columns each to give $100 \%$ activity and $100 \%$ inhibition 
controls, respectively. Single-concentration testing was at $10 \mu \mathrm{M}$ compound concentration. For $\mathrm{pIC}_{50}$ determination, compounds were tested using an 11-point, three-fold dilution series from either $625 \mu \mathrm{M}$ or $6.25 \mu \mathrm{M}$ prepared using a Biomek FX (Beckman Coulter, Wycombe, UK).

To these compound plates, $4 \mu \mathrm{L}$ of an enzyme-PLP solution containing $20 \mathrm{nM}$ BCATm and 40 nM PLP in assay buffer was added. Following this, $4 \mu \mathrm{L}$ of a coupling solution containing $3 \mathrm{mM}$ L-Leucine, $0.5 \mathrm{mM} \alpha$-ketoglutarate, 10 units/mL HRP and $80 \mu \mathrm{M}$ Amplex red in assay buffer was added to initiate the reaction. The coupling solution was incubated on a roller at room temperature in a $15 \mathrm{~mL}$ tube with $1 \mathrm{~mL}$ Agarose immobilised Catalase (Sigma-Aldrich Ltd.) per $10 \mathrm{~mL}$ of coupling solution to 'scrub' the coupling solution prior to addition of Amplex Red and remove background levels of hydrogen peroxide. After a 10 minute incubation, $2 \mu \mathrm{L}$ of $100 \mathrm{mM}$ 4-methyl-2-oxovalerate was added to stop the reaction.

Final assay concentrations were $10 \mathrm{nM}$ BCATm, $20 \mathrm{nM}$ PLP, 5 units per mL HRP, $1.5 \mathrm{mM}$ LLeucine, $0.25 \mathrm{mM}$ alpha-ketoglutarate and $40 \mu \mathrm{M}$ Amplex Red. All additions were performed using a Multidrop Combi (Thermo Fisher Scientific, Waltham, MA). Plates were transferred to an EnVision reader (PerkinElmer) (excitation filter 525/20 nm; emission filter 598/25 nm).

\section{BCAT cellular assay}

Differentiated primary human adipocytes (Zenbio) were challenged overnight using compounds dissolved in HBSS (Gibco 1g/L glucose) complemented with HEPES 10 mM, LSerine $50 \mu \mathrm{M}$ and L-Leucine $150 \mu \mathrm{M}$. Next day cell supernatant were subjected to amino acids determinations using HPLC analysis essentially as previously described. ${ }^{4}$ The method is based 
on automated, online derivatization using o-phthalaldehyde (OPA) for primary amino acids and 9-fluorenylmethyl chloroformate (FMOC) for secondary amino acids, using an Eclipse Plus C18 $3 \times 10 \mathrm{~mm} 3.5 \mu \mathrm{m}$ column to perform reversed phase HPLC (all chemicals and hardware from Agilent Technologies, Inc.). The percentage of inhibition was calculated on leucine concentration remaining compared to vehicle treated cells.

\section{Analogue Searching}

FindAnalogues is an in-house developed PipelinePilot ${ }^{\circledR}$ [Pipeline Pilot (2010) Accelrys Ltd, San Diego] protocol developed to search for analogues of fragment compounds. The protocol used several search methods to retrieve analogues of fragment structures. The tautomers of the input molecule were enumerated prior to searching and core generation using the relevant PipelinePilot component. Tautomers were also enumerated for the core. A core was generated for each input query molecule by iteratively removing terminal chain atoms, stopping at O,N,S. An amide/sulfonamide/ester/acid was cleaved to leave either $\mathrm{N}$ or $\mathrm{C}=\mathrm{O} / \mathrm{SO} 2$. Additional rules break N-linked piperidines to leave N. Terminal Nitrogens are set to [\#7]. [nH] to $n$.

The core was used to conduct a substructure search on the relevant database. The JChem Cartridge was used for enabling chemical structure search and management within Oracle, JChem 5.3, ChemAxon (http://www.chemaxon.com).

Similarity searches were performed on the database using the full query molecule and the ChemAxon fingerprint. Several similarity search metrics ${ }^{22}$ were used: Tversky searches ${ }^{23}$ using the input molecule as both the target and the query with alpha $=0.9$, beta $=0.1$, cut-off $=0.8$; Tanimoto search with similarity cut-off of 0.8 . Additionally a reduced graph ${ }^{24}$ substructure $^{2}$ search was performed with the reduced graph derived from the full query structure. Optionally, 
limits could be placed on the hit list according to the difference in heavy atom count or molecular weight difference between the query and the hit molecule. This was particularly significant for the substructure and Tversky searches to control the size of the hit molecules. The total number of hits from any single query could also be specified, defined as MaxHits in the following. For the SS and RG search, hits were ordered by molecular weight and the MaxHits lowest molecular weight compounds were returned. For the Tversky and Tanimoto search, the MaxHits most similar compounds were returned.

\section{NMR Saturation transfer difference (STD):}

All NMR spectra were recorded in PBS buffer [pH7.2], 100\% D2O, 300K and Bruker Avance $700 \mathrm{MHz}$ spectrometer, equipped with a 5mm cryo-probe and sample changer (Bruker-BioSpin). Sample volume was $180 \mu \mathrm{L}$ in a $3 \mathrm{~mm}$ sample tube (Norrell). A set of reference ${ }^{1} \mathrm{H}$ NMR spectra for individual fragments was recorded in the absence of protein.

Fragments were tested for binding to BCAT in pools of typically 5 compounds per sample at a concentration of $1 \mathrm{mM}$ each. The protein concentration was $10 \mu \mathrm{M}$. Saturation of protein ${ }^{1} \mathrm{H}$ resonances was achieved by continuous wave irradiation at $0.3 \mathrm{ppm}$ for $2 \mathrm{~s}$. A 30-ms spin-lock period was employed before acquisition to allow the residual protein signal to decay. STD spectra were processed and deconvoluted by comparison with the reference spectra of the individual compounds using the TOPSPIN program (Bruker BioSpin). Only STD signals to the left of the waterline (i.e. $>5.5 \mathrm{ppm}$ ) were evaluated. The intensity of the largest resolved signal of each compound was determined and compared to the maximum noise level of the spectrum in the signal-free region between 11 and $12 \mathrm{ppm}$. STD signals with an intensity $4 \mathrm{x}$ above noise level were classified as hits. 


\section{$T_{m}$ Methods}

The protein was diluted to a final concentration $2.4 \mu \mathrm{M}$ in buffer $(25 \mathrm{mM}$ HEPES pH 7.5 containing $25 \mathrm{mM} \mathrm{NaCl}, 20 \mathrm{mM}$ DTT, $20 \mathrm{mM}$ EDTA, $2.5 \%$ glycerol). The PLP (E) form of the enzyme was prepared by incubation with a 100-fold excess of $\alpha$-ketoglutarate for 1 minute at 20 ${ }^{\circ} \mathrm{C}$. The PMP (F) form of the enzyme was prepared by incubation with a 100 -fold excess of 1 leucine for 1 minute at $20^{\circ} \mathrm{C}$. The isoforms of the enzyme were purified by centrifugal ultrafiltration at $15000 \mathrm{xg}$ at $4{ }^{\circ} \mathrm{C}$ for 15 minutes using Vivaspin-6 $10 \mathrm{kDa}$ nominal molecular cut-off spin filters. The retentates were recovered and the volume adjusted to give a final protein concentration of $2.4 \mu \mathrm{M}$. The purified enzymes were stored at $4{ }^{\circ} \mathrm{C}$ until used. Samples were prepared in 96-well plates. $0.5 \mu \mathrm{L}$ of buffer (control), DMSO or compound at $10 \mathrm{mM}$ in DMSO were aliquoted into separate wells. To each well was added $50 \mu \mathrm{L}$ of the required form of the enzyme containing a 1:1000 dilution of Sypro Orange (Invitrogen). The plate was incubated for $1 \mathrm{~min}$ at room temperature and centrifuged for 1 minute at $1000 \mathrm{xg} .20 \mu \mathrm{L}$ aliquots from each well were transferred to wells in sequential rows of a white 96-well plate (Abgene $0.2 \mathrm{~mL}$ semiskirted Thermo-Fast plate; AB-0900/w) and overlaid with $5 \mu \mathrm{L}$ silicon oil. Data were acquired on an Exicycler rt-pcr instrument (Bioneer Inc). Fluorescence intensity was recorded at $0.5^{\circ} \mathrm{C}$ intervals over a temperature range of $4{ }^{\circ} \mathrm{C}$ to $94{ }^{\circ} \mathrm{C}$ at a heating rate of $1{ }^{\circ} \mathrm{C} / \mathrm{min}$. The raw fluorescent intensity signals were exported into Excel csv format. The raw data were normalised using the formula: (cell value-MIN(column data range))/(MAX(column data range)MIN(column data range)) Where "cell value" is the raw fluorescence reading at each temperature point.

The normalised fluorescence intensities versus temperature data were fitted to a standard denaturation isotherm in Grafit5 (Erithacus software). 


\section{BCATm/PLP protein production and crystallisation}

Human branched-chain amino acid aminotransferase mitochondrial (BCATm) (residues 28392) deleted of the N-terminal mitochondria signal peptide (residues 1-27) was cloned into Kanamycin resistant $\mathrm{pET} 28 \mathrm{a}$ via NdeI/XhoI restriction endonuclease sites with an N-terminal 6His-Thrombin cleavage site. This was used to transform E.coli BL21 Star (DE3) (Invitrogen) cells. The transformed cells were grown in turbo media supplemented with glucose and kanamycin, after induction with IPTG $1 \mathrm{mM}$ the temperature was reduced from $37{ }^{\circ} \mathrm{C}$ to $25{ }^{\circ} \mathrm{C}$ and the cells harvested 23 hours later. The human BCATm was purified using a modification of the method described by Conway and Huston ${ }^{25}$, frozen cell pellets were thawed in buffer (25 mM HEPES, pH 7.5, 500 mM NaCl, 4 M Urea, 1 mM DTT, 20 mM Imidazole, Protease Inhibitor Cocktail III (MERCK) containing $0.1 \mathrm{mM}$ Pyridoxal phosphate, $0.2 \mathrm{mg} / \mathrm{ml}$ lysozyme and $10 \mathrm{U} / \mathrm{ml}$ Benzonase (MERCK) and mixed for 30 minutes at room temperature. The cell suspension was sonicated and the cell debris removed by centrifugation at $100,000 \mathrm{~g}$ for $90 \mathrm{mins}$. The supernatant was loaded onto a $5 \mathrm{ml}$ HisTrap HP column (GE Healthcare), washed with 10 bed volumes $(\mathrm{Bv})$ of buffer before running a gradient to $0 \mathrm{M}$ Urea in buffer over $10 \mathrm{Bv}$ at 5 $\mathrm{ml} / \mathrm{min}$. The column was eluted using a series of Imidazole steps 25, 50, 100, 200 and $500 \mathrm{mM}$ in buffer $(10 \mathrm{Bv}$ of each at $5 \mathrm{ml} / \mathrm{min})$. The human BCATm containing fractions $(100 \mathrm{mM} \& 200$ mM Imidazole step) were pooled and concentrated using Amicon Ultra (Millipore) centrifugal ultrafilters with a $30 \mathrm{kDa}(\mathrm{MWCO})$ and further purified using a Superdex 200 column (GE Healthcare). Dimeric human BCATm was pooled and buffer exchanged into thrombin cleavage buffer (50 mM HEPES, pH 7.5, $150 \mathrm{mM} \mathrm{NaCl}, 2 \mathrm{mM} \mathrm{CaCl}$ ) and incubated for 2 hours at room temp with $10 \mathrm{U} / \mathrm{ml}$ of Thrombin (LeeBio). After cleavage, DTT and $\left(\mathrm{NH}_{4}\right)_{2} \mathrm{SO} 4$ was added at 1 $\mathrm{mM}$ and 1.5 M, respectively and the thrombin removed by purification on a Butyl Sepharose HP 
column (GE Healthcare). Human BCATm was eluted using a gradient to $0 \mathrm{M}\left(\mathrm{NH}_{4}\right)_{2} \mathrm{SO} 4$ over 20 Bv. The human BCATm was pooled, buffer exchanged into storage buffer (25 mM HEPES pH 7.5, $25 \mathrm{mM} \mathrm{NaCl}, 20 \mathrm{mM}$ DTT, $20 \mathrm{mM}$ EDTA, $2.5 \%$ glycerol), concentrated to $\sim 10 \mathrm{mg} / \mathrm{ml}$ and snap frozen at $-80{ }^{\circ} \mathrm{C}$. Functional competency was confirmed using the coupled biochemical assay. Structural integrity was confirmed using differential scanning fluorimetry measurements and protein crystalisation.

The purified protein in $25 \mathrm{mM}$ HEPES pH 7.5, $25 \mathrm{mM} \mathrm{NaCl}, 20 \mathrm{mM}$ DTT, $20 \mathrm{mM}$ EDTA, 2.5 $\%$ glycerol and concentrated to at least $7.6 \mathrm{mg} / \mathrm{mL}$ was used for crystallography. Crystals of BCATm were grown by hanging drop vapour diffusion at $20{ }^{\circ} \mathrm{C}$ with microseeding using MDL Morpheus $^{\mathrm{TM}}$ screen condition B2 supplemented with $10 \mathrm{mM}$ DTT in a protein to microseed solution of drop ratio of 1:1. The Hampton Research seed-bead method was used to generate microseeds. The crystals had a yellow hue suggestive of bound PLP cofactor despite none being added during purification or crystallization. The complex with compound 27 was produced from a cocrystal grown under comparable conditions to the holoenzyme but in the presence of the compound (at $25 \mathrm{mM}$ ).

\section{X-ray Crystallography - crystal structures of BCATm/PLP complexed with inhibitors}

Holocrystals were transferred to soaking buffer comprising MDL Morpheus ${ }^{\mathrm{TM}}$ screen condition B2 supplemented with $10 \mathrm{mM}$ or $20 \mathrm{mM}$ DTT and the compound of interest (from a stock solution dissolved in DMSO) at the soaking concentration given in the X-ray summary table (in supplementary data). Crystals were harvested in a cryo-loop and plunge-frozen into liquid nitrogen before loading in a puck for mounting with a sample collector. Data from single crystals were collected at $100 \mathrm{~K}$ either at the Diamond Light Source (Harwell) or on an in-house 
RIGAKU FR-E ${ }^{+}$SUPERBRIGHT/Saturn A200 detector/ACTOR robotic system. Data processing was achieve using DENZO ${ }^{26}, \mathrm{MOSFLM}^{27}$ or $\mathrm{XDS}^{28}$ (within $\mathrm{AUTOPROC}^{29}$ ) and scaled using either SCALEPACK ${ }^{26}$ or $\mathrm{SCALA}^{30}$ within the CCP4 programming suite ${ }^{25}$.

Structures were solved by Fourier synthesis using REFMAC ${ }^{32}$ (via CCP4) starting from a previously determined in house structure, model-building was performed using COOT $^{33}$ and refined using REFMAC via CCP4. The statistics for the data collection and refined co-ordinates are given in Supplementary information. The final crystal structures are deposited in the Protein Data Bank under the accession codes 5I5S-Y and 5I60.

Supporting Information. Statistics for data collection and refined co-ordinates for X-ray crystallography are given in the supporting information. This material is available free of charge via the Internet at http://pubs.acs.org.

\section{AUTHOR INFORMATION}

Corresponding Author

*Phone +44 (0)1438 763875. Email jennifer.a.borthwick@gsk.com

\section{Author Contributions}

The manuscript was written through contributions of all authors. All authors have given approval to the final version of the manuscript.

\section{ACKNOWLEDGMENT}

The authors thank Tony Dean, Laurie Gordon and Andrew Leach for review of the manuscript.

\section{ABBREVIATIONS}


BCAT, branched-chain aminotransferase; BCAA, branched-chain amino acids; CLND, chemiluminescent nitrogen detection; FBDD, fragment based drug discovery; DIPEA, diisopropyl ethylamine; HATU, 1-[Bis(dimethylamino)methylene]-1H-1,2,3-triazolo[4,5-b]pyridinium 3oxide hexafluorophosphate; HTS, high throughput screening; LE, ligand efficiency; LLE ${ }_{\mathrm{AT}}$, lipophilic ligand efficiency defined by Astex; PK, pharmacokinetic; PLP pyridoxal phosphate; PMP, pyridoxamine phosphate; PPB, plasma protein binding; SAR, structure-activity relationship; STD-NMR, saturation-transfer difference nuclear magnetic resonance; $T_{m}$, thermal shift.

\section{REFERENCES}

1. Sweatt, A. J.; Wood, M.; Suryawan, A.; Wallin, R.; Willingham, M. C.; Hutson, S. M. Branched-chain Amino Acid Catabolism: Unique Segregation of Pathway Enzymes in Organ Systems and Peripheral Nerves. Am. J. Physiol. -Endoc. M. 2004, 286, E64-E76.

2. She, P.; Reid, T. M.; Bronson, S. K.; Vary, T. C.; Hajnal, A.; Lynch, C. J.; Hutson, S. M. Disruption of BCATm in Mice Leads to Increased Energy Expenditure Associated with the Activation of a Futile Protein Turnover Cycle. Cell Metab. 2007, 6, 181-194.

3. She, P.; Zhou, Y.; Zhang, Z.; Griffin, K.; Gowda, K.; Lynch, C. J. Disruption of BCAA Metabolism in Mice Impairs Exercise Metabolism and Endurance. J. Appl. Physiol. 2010, 108, 941-949.

4. Bertrand, S. M.; Ancellin, N.; Beaufils, B.; Bingham, R. P.; Borthwick, J. A.; Boullay, A. B.; Boursier, E.; Carter, P. S.; Chung, C. W.; Churcher, I.; Dodic, N.; Fouchet, M. H. ; Fournier, C.; Francis, P. L.; Gummer, L. A.; Herry, K.; Hobbs, A.; Hobbs, C. I.; Homes, P.; Jamieson, C.; Nicodeme, E.; Pickett, S. D.; Reid, I. H.; Simpson, G. L.; Sloan, L. A.; Smith, S. E.; Somers, D. 
O.; Spitzfaden, C.; Suckling, C. J.; Valko, K.; Washio, Y.; Young, R. J. The Discovery of in Vivo Active Mitochondrial Branched-Chain Aminotransferase (BCATm) Inhibitors by Hybridizing Fragment and HTS Hits. J. Med. Chem.2015, 58, 7140-7163.

5. Deng, H.; Zhou, J.; Sundersingh, F. S.; Summerfield, J.; Somers, D.; Messer, J. A.; Satz, A. L.; Ancellin, N.; Arico-Muendel, C. C.; Bedard, K. L.; Beljean, A.; Belyanskaya, S. L.; Bingham, R.; Smith, S. E.; Boursier, E.; Carter, P.; Centrella, P. A.; Clark, M. A.; Chung, C. W.; Davie, C. P.; Delorey, J. L.; Ding, Y.; Franklin, G. J.; Grady, L. C.; Herry, K.; Hobbs, C.; Kollmann, C. S.; Morgan, B. A.; Kaushansky, L. J.; Zhou, Q. Discovery, SAR, and X-ray Binding Mode Study of BCATm Inhibitors from a Novel DNA-Encoded Library. ACS Med. Chem. Lett. 2015, 6, 919-924.

6. Scanlon, M. Inhibitors of BCATm: A Tough Nut To Crack. J. Med. Chem. 2015, 58, 71387139.

7. Whittaker, M.; Law, R. J.; Ichihara, O.; Hesterkamp, T.; Hallett, D. Fragments: Past, Present and Future. Drug Discov. Today: Technologies 2010, 7 e163-e171.

8. Schiebel, J.; Radeva, N.; Köster, H.; Metz, A.; Krotzky, T.; Kuhnert, M.; Diederich, W. E.; Heine, A.; Neumann, L.; Atmanene, C.; Roecklin, D.; Vivat-Hannah, V.; Renaud, J. P.; Meinecke, R.; Schlinck, N.; Sitte, A.; Popp, F.; Zeeb, M.; Klebe, G. One Question, Multiple Answers: Biochemical and Biophysical Screening Methods Retrieve Deviating Fragment Hit Lists. ChemMedChem 2015, 10, 1511-1521.

9. Alex, A. A.; Flocco, M. M. Fragment-Based Drug Discovery: What has it Achieved so Far? Curr. Top. Med. Chem. 2007, 7, 1544-1567. 
10. Chessari, G.; Woodhead, A. J. From Fragment to Clinical Candidate - a Historical Perspective. Drug Discov. Today 2009, 14 , 668-675.

11. Hajduk, P. J.; Greer, J. A Decade of Fragment-Based Drug Design: Strategic Advances and Lessons Learned. Nat. Rev. Drug Discov. 2007, 6, 211-219.

12. Hutson, S. Structure and Function of Branched Chain Aminotransferases. Progress in Nucleic Acid Research and Molecular Biology, 2001, 70, 175-206. Academic Press, San Diego.

13. Hann, M. M.; Leach, A. R.; Harper, G. Molecular Complexity and its Impact on the Probability of Finding Leads for Drug Discovery. J. Chem. Inf. Comp. Sci. 2001, 41, 856-864.

14. Ludwig, C.; Guenther, U. L. Ligand Based NMR Methods for Drug Discovery. Front Biosci. 2009, 14, 4565-4574.

15. Gozalbes, R.; Carbajo, R. J.; Pineda-Lucena, A. Contributions of Computational Chemistry and Biophysical Techniques to Fragment-Based Drug Discovery. Curr. Med. Chem. 2010, 17, 1769-1794.

16. Hopkins, A. L.; Groom, C. R.; Alex, A. Ligand Efficiency: a Useful Metric for Lead Selection. Drug Discov. Today 2004, 9, 430-431.

17. Mortenson, P.; Murray, C. Assessing the Lipophilicity of Fragments and Early Hits. J. Comput. -Aided Mol. Des. 2011, 25, 663-667.

18. Fischer, M.; Hubbard, R. E. Fragment-Based Ligand Discovery. Mol. Interv.2009, 9, 2230. 
19. Ishikawa, M.; Hashimoto, Y. Improvement in Aqueous Solubility in Small Molecule Drug Discovery Programs by Disruption of Molecular Planarity and Symmetry. J. Med. Chem. 2011, $54,1539-1554$.

20. Murray, C. W.; Rees, D. C. The Rise of Fragment-Based Drug Discovery. Nat. Chem. 2009, 1, 187-192.

21. Azizian, J.; Mohammadi, A. A.; Karimi, A. R.; Mohammadizadeh, M. R. A Stereoselective Three-Component Reaction: $\mathrm{KAl}\left(\mathrm{SO}_{4}\right)_{2} \cdot 12 \mathrm{H}_{2} \mathrm{O}$, an Efficient and Reusable Catalyst for the OnePot Synthesis of cis-Isoquinolonic Acids. J. Org. Chem. 2004, 70, 350-352.

22. Willett, P.; Barnard, J. M.; Downs, G. M. Chemical Similarity Searching. J. Chem. Inf. Comp. Sci. 1998, 38, 983-996.

23. Tversky, A. Features of Similarity. Psychol. Rev. 1977, 327-352.

24. Harper, G.; Bravi, G. S.; Pickett, S. D.; Hussain, J.; Green, D. V. S. The Reduced Graph Descriptor in Virtual Screening and Data-Driven Clustering of High-Throughput Screening Data. J. Chem. Inf. Comp. Sci. 2004, 44, 2145-2156.

25. Bailey, S. The CCP4 Suite: Programs for Protein Crystallography. Acta Crystallogr., Sect.D: Biol.Crystallogr. 1994, 760-763. 
Insert Table of Contents Graphic and Synopsis Here

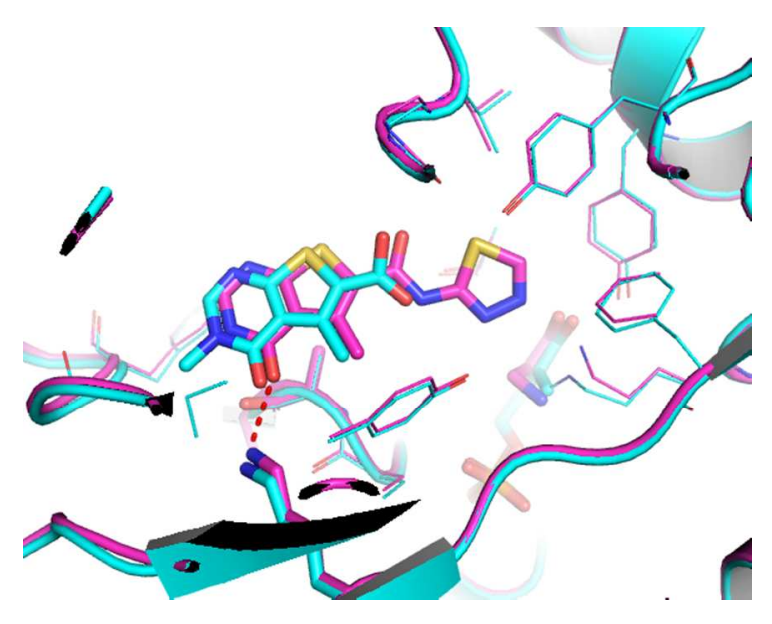

21

22

23

24

25

26

27

28

29

30

31

32

33

34

35

36

37

38

39

40

41

42

43

44

45

46

47

48

49

50

51

52

53

54

55

56

57

58

59

60

ACS Paragon Plus Environment 